
\title{
(s)
}

\section{Oxidation Behavior of Hf-Modified Aluminide Coatings on Inconel- 718 at $1050^{\circ} \mathrm{C}$}

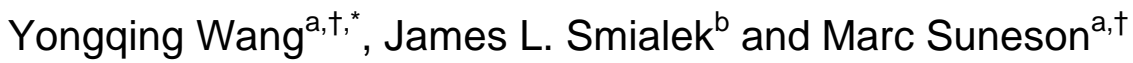 \\ ${ }^{a}$ SIFCO Minneapolis, Turbine Component Services, 2430 North Winnetka Avenue, Minneapolis, MN, 55427, USA \\ ${ }^{b}$ NASA Glenn Research Center, Cleveland, OH 44135, USA
}

\begin{abstract}
Simple $\beta$-NiAl, Hf-modified $\beta$-NiAl, Pt-diffused, Pt-modified $\beta$-(Ni,Pt)Al $+\xi-\mathrm{PtAl}_{2}$, and Hf-Ptmodified $\beta-(\mathrm{Ni}, \mathrm{Pt}) \mathrm{Al}$ were cyclic oxidation tested at $1050^{\circ} \mathrm{C}$ in air on Inconel-718 substrates for up to $4370 \mathrm{~h}$. The Pt-diffused specimen failed most quickly, $<100 \mathrm{~h}$, while the simple $\beta$-NiAl aluminide maintained a positive weight change for $\sim 1300 \mathrm{~h}$. The Pt-modified aluminides clearly improved the cyclic oxidation behavior of both simple and $\mathrm{Hf}$-modified aluminides, sustaining a zero weight change only after 3600 and $4000 \mathrm{~h}$, respectively. The $\mathrm{Hf}$ additions did not immediately appear to produce as strong an improvement as expected, however, they were more highly ranked when normalized by coating thickness. They also decreased surface rumpling, important for TBC durability. Hf-rich NiAl grain boundaries, formed during coating processing, resulted in $\mathrm{HfO}_{2}$ particles in the scales and oxide pegs at the metal interface, all suggesting some level of over-doping. The high sulfur content of the substrate influenced spalling to bare metal and re-healing to less protective $\mathrm{Ni}(\mathrm{Al}, \mathrm{Cr})_{2} \mathrm{O}_{4}$ spinel-type and $(\mathrm{Ti}, \mathrm{Cr}, \mathrm{Nb}) \mathrm{O}_{2}$ rutile scales. The evolution of these surface features have been documented over 100 to $4370 \mathrm{~h}$ of exposure. The coating aluminum content near failure was $\sim 2-3$ wt. \%.
\end{abstract}

Received on 07-03-2014 Accepted on 10-04-2014 Published on 25-06-2014

Keywords: Hafnium, aluminide coatings, oxidation testing, Inconel 718, vapor phase process.

\section{INTRODUCTION}

Diffusion aluminide coatings, as either environmental coatings or as bond coats in thermal barrier coating (TBC) systems, have been widely applied on turbine engine hot section blades and vane segments as protection from the aggressive conditions of industrial and aero-gas turbines. This protection derives from the promotion of a slow growing $\mathrm{Al}_{2} \mathrm{O}_{3}$ oxide scale that acts as a barrier against oxidation and hot corrosion. Ideally, the alumina scale should be slowgrowing, adherent, compact, and continuous to be effective under cyclic, high temperature, corrosive engine environments [1]. Excessive scale spallation from the bond coat leads to TBC failure, and excessive scale growth contributes to scale spallation $[2,3]$.

The performance of aluminide coatings has been improved to meet the requirements of increasing turbine operating temperatures by doping the aluminide coatings with other elements. Pt-doped aluminide coatings, produced by

"SIFCO Minneapolis, Turbine Component Services, 2430 North Winnetka Avenue, Minneapolis, MN, 55427, USA; Tel: 1-336-969-1246; Fax: 1-336-9691539; E-mails: yongqingblessing@gmail.com, yongqing.wang@siemens.com

${ }^{\dagger}$ Current Address: Siemens Energy, Inc. at 3050 Westinghouse Road, Rural Hall, NC, 27045 and. Marc Suneson is at Mohawk Metallurgical Associates. electroplating a thin layer of $\mathrm{Pt}$ followed by aluminizing, have increased coating lifetimes significantly [4-9]. Currently, the single phase $\beta$-(Ni,Pt)Al coating has been an accepted industrial standard as the bond coat for TBCs [10]. However, the cost of Pt-modified aluminide coatings is higher due to the extra electroplating step as well as the price of Pt. The role of $\mathrm{Pt}$ is complex and has been shown to counteract sulfur segregation, enable alumina formation at lower Al content, and maintain a higher Al surface concentration [11-15]. Nevertheless, continued growth of an alumina scale and interdiffusion with the substrate result in Al depletion in the $\beta$ $\mathrm{NiAl}$ coatings and transformation from $\beta-\mathrm{NiAl}$ to $\gamma^{\prime}-\mathrm{Ni}_{3} \mathrm{Al}$ during cycling [16, 17]. The associated volume change, coupled with CTE mismatch with superalloy substrates, results in coating surface "rumpling" that accelerates delamination of the ceramic top coat when used in a TBC system $[18,19]$. As a result, there is a desire to incorporate other elements either to replace $\mathrm{Pt}$ in aluminide coatings or to further improve the performance of Pt-modified aluminide coatings. Hf doping is one approach of growing interest. The benefits of $\mathrm{Hf}$ are well documented in previous studies of various $\mathrm{Hf}$-doped cast alloys, such as Co-10Cr-11Al (wt. $\%)+\mathrm{Hf}$ [20-23], Ni-10Cr-8Al (wt. \%)+Hf [24], NiAl+Hf [25-31], $\mathrm{Y}-\mathrm{Ni} / \mathrm{Y}^{\prime}-\mathrm{Ni}_{3} \mathrm{Al}+\mathrm{Hf}$ [32], FeCrAl+Hf [33, 34], as well as plasma sprayed NiCoCrAlHfY coatings [35]. The various mechanisms 
by which performance is enhanced by $\mathrm{Hf}$ and other reactive elements have been studied in detail, as summarized in review papers [36-39].

$\mathrm{Hf}$ additions, in particular, markedly improve scale adherence and reduce the scale growth rate. Furthermore, it has recently been proposed that $\mathrm{Hf}$ additions may decrease the surface rumpling [40]. Accordingly, promising results from bulk alloys are being transferred to coating applications. It is well known that interdiffusion with various substrates may provide unintentional compositional changes and provide the primary mode of Al loss, both leading to oxidative degradation [41, 42]. Thus it is paramount to demonstrate acceptable performance for future applications by oxidation testing and characterization of actual $\mathrm{Hf}$-doped aluminide coatings.

Regarding such diffusion coatings, $\mathrm{Hf}$ may be incorporated by interdiffusion from Hf-containing substrates [40, 43-44] or from the coating process environment [45]. For industrial applications, it is more practical and versatile to incorporate $\mathrm{Hf}$ from the coating process. However, co-deposition has been proven to be problematic $[31,46]$. Thus much of what is known about $\mathrm{Hf}$ effects in $\beta$-NiAl had initially been gained from $\mathrm{Hf}$-doped model cast alloys or where the $\mathrm{Hf}$-doping was accomplished by substrate interdiffusion or pre-sputtered $\mathrm{Hf}$ [28, 47-48].

Many of the process fundamentals of co-deposited aluminides were first presented by Kim et al. [46], showing important $\mathrm{HfCl}_{3} / \mathrm{AlCl}_{3}$ activator ratios producing various $\mathrm{Hf}$ concentrations and grain boundary segregation of $\mathrm{Hf}$. Recently a commercial coating patent application (Howmet) described the use of an optimized Pt-electroplate and prehafnizing to $\mathrm{Hf}_{2} \mathrm{Pt}_{3} \mathrm{Ni}_{x} \mu$-phase compounds, followed by aluminizing [49]. The resultant $\mathrm{Hf}-\mathrm{Pt}-\mathrm{NiAl}$ bond coatings have been shown to be capable of a 3-5x improvement in TBC life (i.e., ca. $3000-3500$ cycles at $1135^{\circ} \mathrm{C}, 45 \mathrm{~min}$. /cycle for 7YSZ) [49].

Finally work at SIFCO $[50,51]$ showed that $\mathrm{Hf}$ could be successfully incorporated into aluminide coatings on Ni-base superalloys by using an industrial vapor phase coating process. The various process parameters studied previously for the base coating included Pt electroplate thickness, Al content in the source alloy, and diffusion heat treatments for Mar M-247, Inconel 625, and Waspalloy substrates [50]. In general, greater $\mathrm{Al}$ and $\mathrm{Pt}$ amounts led to greater amounts of the $\xi-\mathrm{PtAl}_{2}$ phase, subsequently decreased by diffusion annealing. Hf-doped simple NiAl or Pt-doped NiAl coatings were then produced on six different alloys, including aeroengine hot section components. In general, extremely $\mathrm{Hf}$-rich coating grain boundaries were identified along with $\mathrm{Hf}$-rich particles dispersed throughout the thickness and enrichment at the coating interface, yielding a relatively inhomogeneous $\mathrm{Hf}$ distribution.

Despite a high level of interest in this and other such coating advancements, there is relatively little information available characterizing the details of their oxidation behavior, especially for coatings produced by commercial processes. Indeed most $\mathrm{Hf}, \mathrm{Zr}$-doped coating oxidation studies have been for alternate processing routes, such as $\mathrm{Hf}$ presputtering or EB-PVD NiAl $(+\mathrm{Cr}, \mathrm{Zr})[47,52]$. One doped aluminizing study found beneficial trends in $1150^{\circ} \mathrm{C}$ cyclic oxidation performance with the amount of $\mathrm{HfO}_{2}$ or $\mathrm{ZrO}_{2}$ pack sources, but such studies are rare [53].

Accordingly, the purpose of the present study was to characterize the cyclic oxidation behavior of some developmental Hf-doped aluminide coatings on a generic $\mathrm{Ni}$ base superalloy, Inconel 718 . It is recognized that low sulfur, oxidation resistant $2^{\text {nd }}$ and $3^{\text {rd }}$ generation single crystal alloys may be a more critical class of substrates. Their excellent performance with $\mathrm{Ni}(\mathrm{Pt}) \mathrm{Al}$ bond coats and TBCs enables their widespread use as turbine blades and vanes. However, Inconel 718 was chosen for this early developmental study as one of those previously studied during coating development and one which does not contain $\mathrm{Hf}$ that might obscure $\mathrm{Hf}$ effects from just the coating. Simple $\beta$-NiAl, Hf-modified $\beta$ $\mathrm{NiAl}$, Pt-diffused, Pt-modified $\beta-(\mathrm{Ni}, \mathrm{Pt}) \mathrm{Al}+\xi-\mathrm{PtAl} \mathrm{I}_{2}$, and Hf-Ptmodified $\beta$-(Ni,Pt)Al coatings were oxidized at $1050^{\circ} \mathrm{C}$ in air, using primarily $20 \mathrm{hr}$ cycles. Unlike many cyclic oxidation studies of bulk or coated materials, periodic examinations provided insightful demonstration of the evolution of surface scale structures from initial oxidation, through the maximum in weight gain, to where the systems were steadily losing weight by spallation and finally exhibited a negative weight change. Such exposures went up to $\sim 4400 \mathrm{~h}$ for the Hf-PtNiAl coating.

\section{EXPERIMENTAL PROCEDURE}

Specimens for this study were machined from conventional Inconel 718 sheet purchased from Haynes International with a certified composition of $53.52 \mathrm{Ni}-17.64 \mathrm{Fe}-18.61 \mathrm{Cr}-5.15 \mathrm{Nb}-$ 3.02Mo-0.2Co-1.03Ti-0.51 Al-0.05Si-0.22Mn-0.02Cu-0.03C$0.003 \mathrm{~S}$ (wt. \%). Five different coatings were tested: diffused $\mathrm{Pt}$, NiAl, Hf-NiAl, Pt-NiAl, and Hf-Pt-NiAl. The specimen sizes were approximately $30 \mathrm{~mm} \times 25 \mathrm{~mm} \times 1.6 \mathrm{~mm}$ for the NiAl coating and $40 \mathrm{~mm} \times 30 \mathrm{~mm} \times 1.6 \mathrm{~mm}$ for the others. All the $\mathrm{Pt}$ coatings were first electroplated with 4-7 $\mu \mathrm{m} \mathrm{Pt}$ and diffusion heat treated at $1052^{\circ} \mathrm{C}$ for $1 \mathrm{~h}$ in vacuum [51]. All four aluminide coatings were produced at $1080^{\circ} \mathrm{C}$ for $3-4 \mathrm{~h}$ by a vapor phase coating process using $\mathrm{Cr}-\mathrm{Al}$ alloy sources and $\mathrm{AlF}_{3}$ activator [51]. Hf-doped aluminides were produced with $\mathrm{HfO}_{2}$ powder added in the retort [50].

Specimens were ultrasonically cleaned in water and acetone, and then cyclically oxidized side by side in an F48020 Thermolyne, benchtop muffle furnace in air. In each cycle, specimens were manually loaded at a furnace temperature of $850^{\circ} \mathrm{C}$, automatically ramped to $1050^{\circ} \mathrm{C}$ over 35 minutes, held at $1050^{\circ} \mathrm{C}$ for a specified time, generally $20 \mathrm{~h}$ per cycle. The samples were then cooled to $850^{\circ} \mathrm{C}$ in 20 minutes, unloaded manually, further cooled in ambient air, and weighed. Only the dwell time, the time length from the point 
when the temperature reaches $1050^{\circ} \mathrm{C}$ to the point when the furnace starts to cool down, was counted as oxidation test time. The hot dwell was $5 \mathrm{~h} / \mathrm{cycle}$ for the first $40 \mathrm{~h}, 20 \mathrm{~h} / \mathrm{cycle}$ between $40 \mathrm{~h}$ and $3320 \mathrm{~h}$, and $150 \mathrm{~h} / \mathrm{cycle}$ between $3320 \mathrm{~h}$ and $4370 \mathrm{~h}$. The testing condition in this research is a little bit different from the traditional cyclic oxidation testing condition in which the sample is directly loaded and unloaded at the test temperature. The sample weights were measured with a Scientech SA 80 balance to $0.1 \mathrm{mg}$, and the specific weight change was calculated using the entire sample surface area. The evolution of the surface scale morphology was tracked at various stages during oxidation testing. Both surface morphology and the cross-section microstructures were examined after coating failure $\left(\sim 0.3 \mathrm{mg} / \mathrm{cm}^{2}\right.$ weight loss, i.e., just crossing zero weight change) using a JEOL scanning electron microscope (SEM) equipped with Oxford energy dispersive spectroscopy (EDS).

\section{RESULTS}

\subsection{Coating Characterization Prior to Oxidation Testing}

The as-coated surface morphology and cross-section information were obtained from a duplicate specimen,

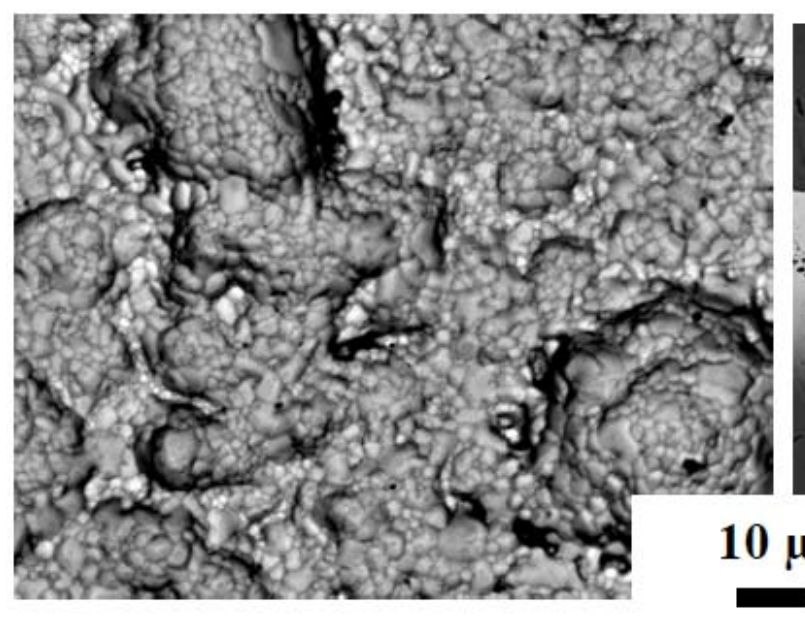

(a)

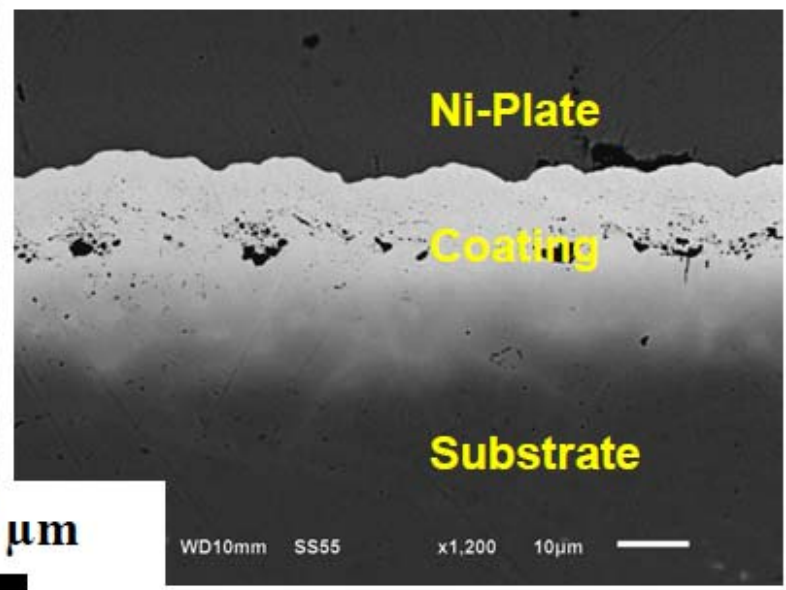

(b)

Figure 1: SEM backscattered electron micrographs of as-diffused Pt-coating.

(a) Surface morphology, and (b) Cross-section.

Table 1: Summary of Estimated Coating Compositions on Inconel 718 before and after Cyclic Oxidation at $1050^{\circ} \mathrm{C}$ (wt. $\%$ by EDS, $\sim 20 \mathrm{~h} /$ Cycle)

\begin{tabular}{|c|c|c|c|c|c|c|c|c|}
\hline & $\mathrm{Ni}$ & Al & $\mathrm{Cr}$ & $\mathrm{Fe}$ & & $\mathrm{Nb}$ & Mo & $\mathbf{P t}$ \\
\hline IN-718 & 53.2 & 0.5 & 18.6 & 18.5 & 1 & 5.2 & 3 & \\
\hline Pt diffused & 21.1 & 0.7 & 9.2 & 8.5 & 1.1 & 3.9 & 2.2 & 52.7 \\
\hline$\Delta$ wt $\%$ & 22.3 & -0.7 & -0.7 & 9.1 & -1.1 & -3.9 & 1.9 & -26.3 \\
\hline Pure NiAl & 48.6 & 34.8 & 5.3 & 11.2 & & & & \\
\hline$\Delta$ wt $\%$ & 24.3 & -26.6 & -2.0 & -4.6 & 2.2 & 6.9 & 0 & 0 \\
\hline $\mathrm{Hf}-\mathrm{NiAl}$ & 45.2 & 32 & 7.5 & 15.3 & & & & \\
\hline $2000 \mathrm{~h}$ & 55.1 & 2.6 & 16.5 & 17.1 & 1.1 & 5 & 2.6 & \\
\hline$\Delta$ wt $\%$ & 9.9 & -29.4 & 9.0 & 1.8 & 1.1 & 5 & 2.6 & 0 \\
\hline Pt-NiAl & 42.4 & 18.8 & 4.9 & 5.5 & 0.4 & & & 28.5 \\
\hline Hf-Pt-NiAl & 43.4 & 29.2 & 0.9 & 4.4 & & & & 22.1 \\
\hline $4370 \mathrm{~h}$ & 53.6 & 2.2 & 16.6 & 16.8 & 1.1 & 4.4 & & 5.3 \\
\hline$\Delta \mathrm{wt} \%$ & 10.2 & -27.0 & 15.7 & 12.4 & 1.1 & 4.4 & 0 & -16.8 \\
\hline
\end{tabular}

MDC150L. 


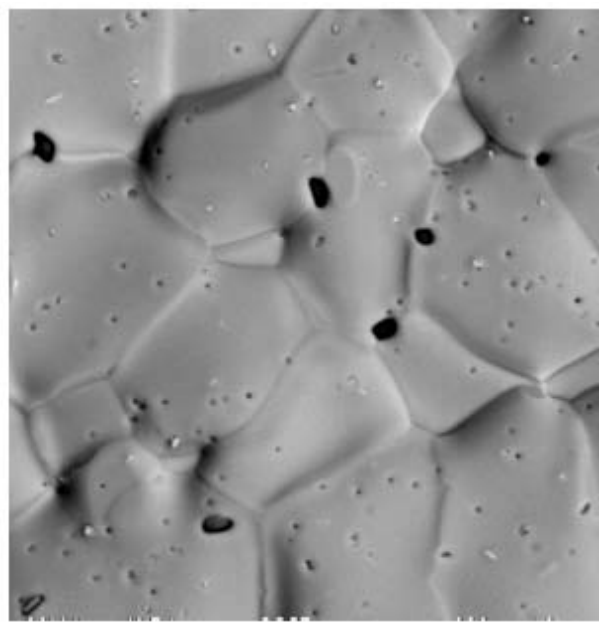

(a)

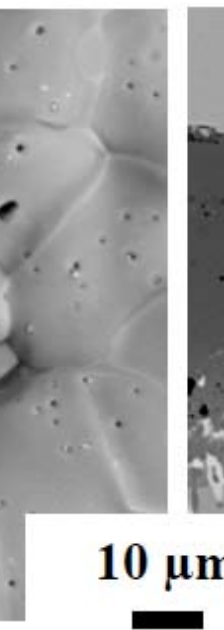

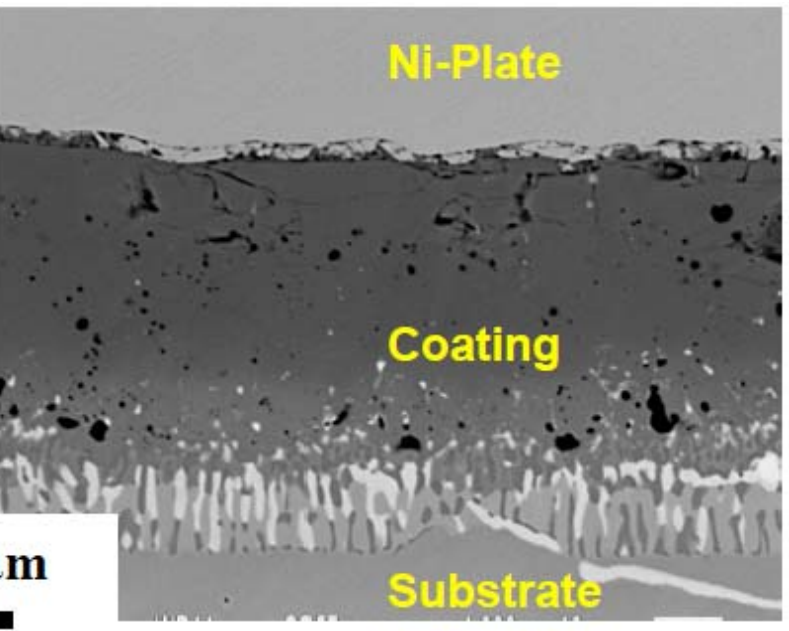

(b)

Figure 2: SEM backscattered electron micrographs of as-processed NiAl coating.

(a) Surface morphology, and (b) Cross-section.

processed along with the oxidation specimens. Some details were published previously $[50,51]$, but major features are presented below:

\section{Diffused Pt}

After electroplating and vacuum diffusion annealing for $1 \mathrm{~h}$ at $1052^{\circ} \mathrm{C}$, the Pt-coating surface shows a fine grain structure (Figure 1a). Coating EDS analysis, summarized in Table 1, indicated the surface was very Pt-rich with an estimated composition of (wt. \%) 52.7Pt-21.1 Ni-9.2Cr-8.5Fe-3.9Nb0.7Al-1.1Ti-2.2Mo-0.6Co. The Pt-rich layer was observed to be around $30 \mu \mathrm{m}$ in cross-section (Figure 1b).

\section{NiAl}

The simple $\beta$-NiAl coatings were produced by the industrial vapor phase coating process. The as-coated surface showed the typical large, 25-50 $\mu \mathrm{m}$ polyhedral shaped grains (Figure 2a). The EDS surface composition was $48.6 \mathrm{Ni}-34.8 \mathrm{Al}-5.3 \mathrm{Cr}$ -
11.2Fe (wt. \%), indicating Al-rich $\beta$-NiAl phase (Stoichiometric $\beta-\mathrm{NiAl}$ is $\sim 31.5$ wt. \% Al). In cross-section (Figure $\mathbf{2 b}$ ), the coating was measured to be $62 \mu \mathrm{m}$ thick and composed of two layers: an outer $\beta-\mathrm{NiAl}$ phase additive layer and an interdiffusion layer.

\section{Hf-NiAl}

The Hf-doped $\mathrm{NiAl}$ coating was also produced by the industrial vapor phase coating process. The as-coated surface (Figure 3a) showed 10-20 $\mu \mathrm{m}$ polyhedral shaped grains with a composition of 45.2Ni-32.0Al-7.5Cr-15.3Fe (wt. $\%$ ), indicating $\beta-\mathrm{NiAl}$. The bright grain boundaries at the surface were rich in $\mathrm{Hf}$. In cross-section (Figure $3 \mathbf{b}$ ), the coating was measured to be $58 \mu \mathrm{m}$ thick and exhibited bright $\mathrm{Hf}$-rich precipitates near the coating surface and at the interface between the outer $\beta-\mathrm{NiAl}$ layer and the interdiffusion layer.

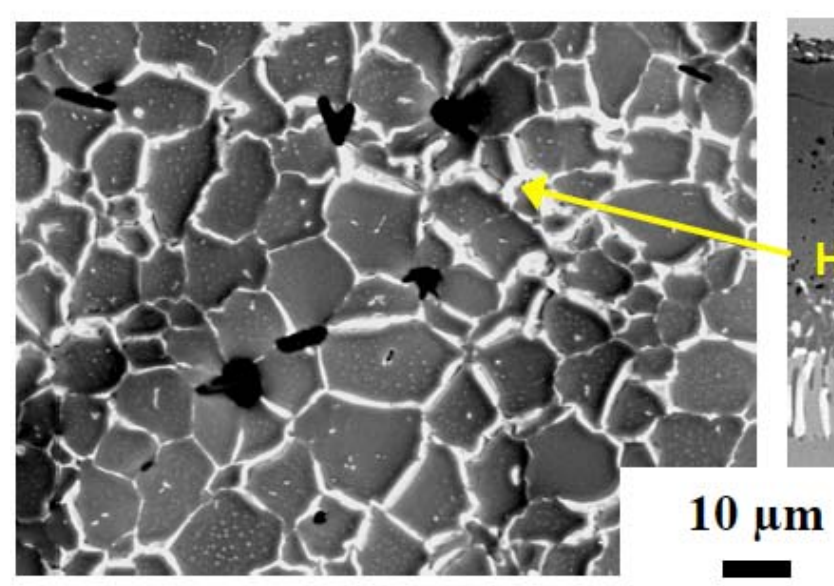

(a)

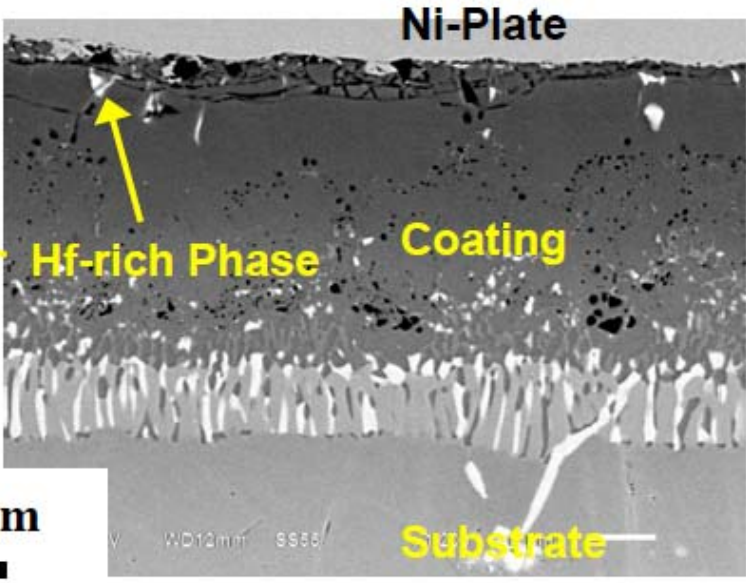

(b)

Figure 3: SEM backscattered electron micrographs of as-processed Hf-NiAl coating.

(a) Surface morphology, and (b) Cross-section. 


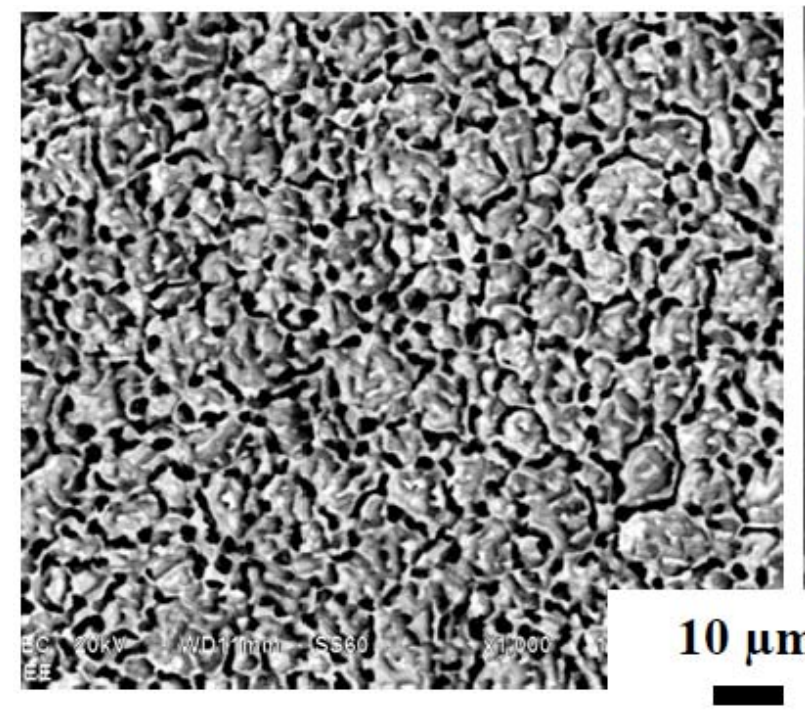

(a)

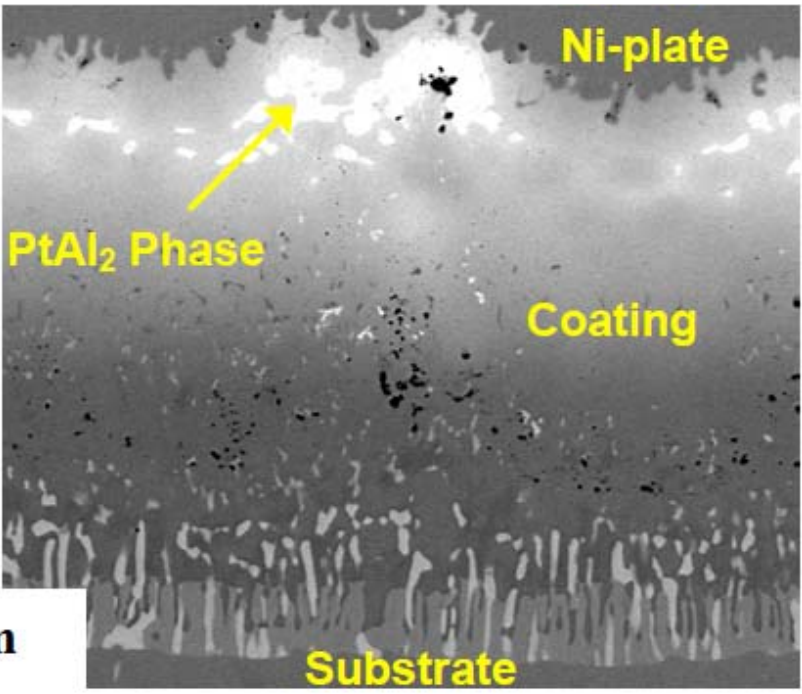

(b)

Figure 4: SEM backscattered electron micrographs of as-processed Pt-NiAl coating.

(a) Surface morphology, and (b) Cross-section.

\section{Pt-NiAl}

The Pt-NiAl coating was synthesized via Pt electroplating, vapor phase aluminizing, and heat treating at $1121^{\circ} \mathrm{C}$ for $2 \mathrm{~h}$ in vacuum. The coating surface (Figure 4a) was irregular, with a network of $\sim 5 \mu \mathrm{m}$ cusps and dimples. The surface composition was $42.4 \mathrm{Ni} 18.4 \mathrm{Al}-4.9 \mathrm{Cr}-5.5 \mathrm{Fe}-0.4 \mathrm{Ti}-28.5 \mathrm{Pt}$ (wt. $\%$ ), suggesting a hypostoichiometric $\beta$-(Ni,Pt)Al phase in the 2-phase region with $\gamma^{\prime}-\mathrm{Ni}_{3} \mathrm{Al}$. The irregular cusp-like surface is also visible in cross-section (Figure $\mathbf{4 b}$ ). The coating was $101 \mu \mathrm{m}$ thick and consisted of two layers: an outer additive layer and an interdiffusion layer. Some bright $\xi-\mathrm{PtAl}_{2}$ phase particles remained in the outer layer after the heat treatment.

\section{Hf-Pt-NiAl}

The Hf-Pt-doped NiAl coating was prepared via $\mathrm{Pt}$ electroplating, vapor phase co-aluminizing \& hafnizing, and heat treating at $1121^{\circ} \mathrm{C}$ for $2 \mathrm{~h}$ in vacuum. The coating also showed an irregular coating surface with $\sim 5 \mu \mathrm{m}$ cusps (Figure 5a), as did the other Pt-doped NiAl coating. The surface was composed of bright ridge areas (A) and gray areas $(B)$ in Figure $\mathbf{5 b}$. The bright ridge phase is $\mathrm{Hf}-\mathrm{Pt}$-rich with a composition of $20.8 \mathrm{Hf}-36.7 \mathrm{Ni}-18.3 \mathrm{Al}-0.7 \mathrm{Cr}-4.0 \mathrm{Fe}-$ $1.1 \mathrm{Co}-18.5 \mathrm{Pt}$ (wt. \%), while the gray phase is $\beta-(\mathrm{Ni}, \mathrm{Pt}) \mathrm{Al}$ with a composition of $43.4 \mathrm{Ni}-29.2 \mathrm{Al}-0.9 \mathrm{Cr}-4.4 \mathrm{Fe}-22.1 \mathrm{Pt}$ (wt.\%). In cross-section (Figure $5 \mathbf{c}$ ), the coating was measured to be 71 $\mu \mathrm{m}$ thick, again showing the irregular surface with the Hf-Ptrich phases. Within the coating, fine bright Hf-rich particles were observed in the outer $\beta$-(Ni,Pt)Al layer.

It is known that ppm levels of sulfur (S) have a detrimental effect on alumina scale adhesion and cyclic oxidation resistance of aluminides and that $\mathrm{Hf}$ can be effective in restoring adhesion in the presence of sulfur [28, 54-55]. Consequently, the $\mathrm{Hf}$ and $\mathrm{S}$ depth profiles were determined by Glow-Discharge Mass Spectrometry (GDMS) and compared for the NiAl and Hf-NiAl coatings in Figure 6. The S distribution in the NiAl coating was around $7-40 \mathrm{ppm}$ in the outer layer and showed a peak value of $269 \mathrm{ppm}$ at the interface between the outer and interdiffusion layers. Similarly, S in the Hf-NiAl coating was 7-50 ppm within the outer layer, and the peak value at the interface was $126 \mathrm{ppm}$. The $\mathrm{Hf}$ distribution in the NiAl coating was only $1 \mathrm{ppm}$ within the outer layer and a peak value of $8 \mathrm{ppm}$ at the interface with the interdiffusion layer. In contrast, $\mathrm{Hf}$ in the $\mathrm{Hf}-\mathrm{NiAl}$ coating was 0.39 wt. \% at the external coating surface and $0.05-0.11$ wt. $\%$ within the outer additive layer.

The above comparison indicated that the $S$ contents were comparable in both coatings and consistent with the $30 \mathrm{ppmw}$ (0.003 wt. \%) S content in the substrate; while $\mathrm{Hf}$ in the $\mathrm{Hf}$ $\mathrm{NiAl}$ coating was substantially higher. Since the substrate did not contain any $\mathrm{Hf}$ and no $\mathrm{Hf}$ source material was used in the coating process for the simple NiAl coating, the minor $\mathrm{Hf}$ in that coating was expected to result from contamination. It can be ignored for oxidation effects because of the low levels. It should be mentioned that coating depth here was converted from sputtering time and a sputtering rate typical for GDMS analysis. Furthermore, significant uncertainty inherent in the GDMS techniques (possibly above 20\%), due to non-uniform sputtering and phase inhomogeneity, may give rise to some systematic errors.

\subsection{Cyclic Oxidation Weight Change}

A number of points are raised in showing and analyzing the weight change data below. Briefly, all coatings show an increase in weight due to oxidation, exhibit a maximum, and then weight loss due to spalling. This shift occurs latest for the Pt-NiAl and Pt-Hf-NiAl coatings. A parabolic plot of weight vs $t^{1 / 2}$ indicates an initial transient for all coatings and a specified range to best fit parabolic behavior between $\sim 20$ - 


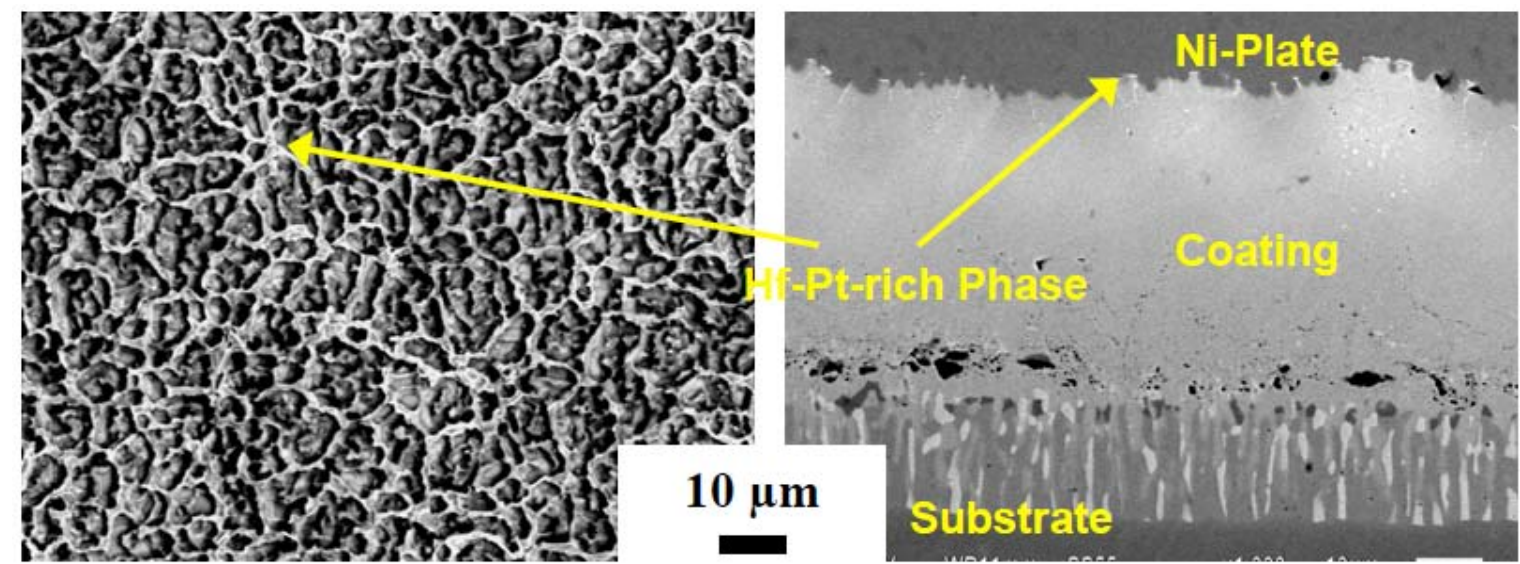

(a)

(b)

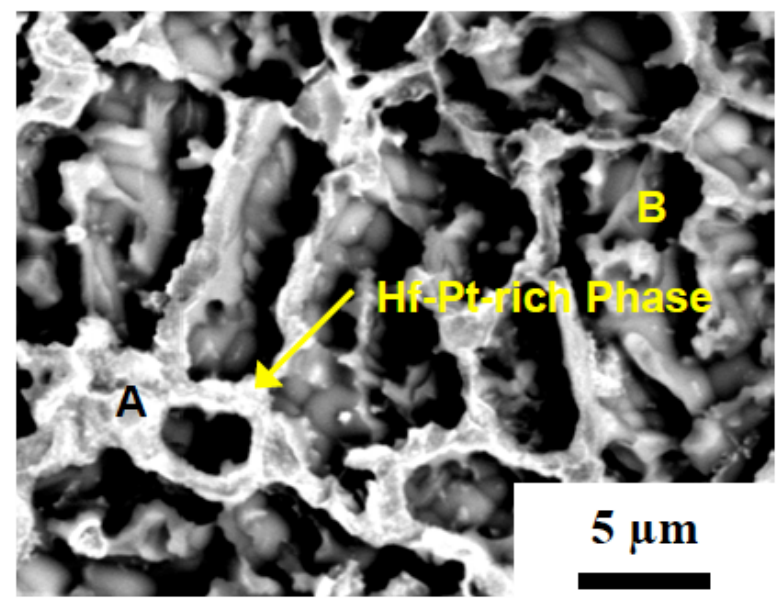

(c)

Figure 5: SEM backscattered electron micrographs of as-processed Hf-Pt-NiAl coating. (a) Surface morphology, (b) Cross-section, and (c) Hf-Pt-rich phase on coating surface.

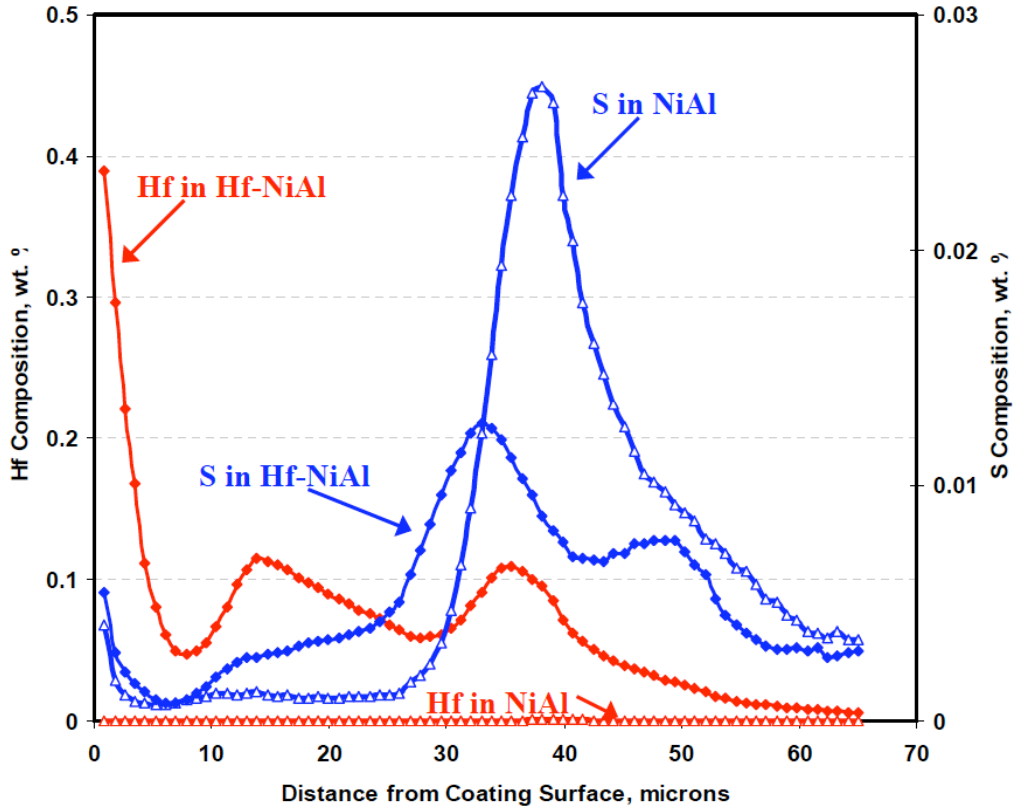

Figure 6: GDMS composition depth profiles of $\mathrm{Hf}$ and $\mathrm{S}$ in the $\mathrm{NiAl}$ and $\mathrm{Hf}-\mathrm{NiAl}$ coatings. 
Table 2: Characteristic Cyclic Oxidation Parameters for Coatings on Inconel 718. $\left(1050^{\circ} \mathrm{C}, \sim 20 \mathrm{~h} / \mathrm{cycle}\right) \mathrm{t}_{\mathrm{o}}$, Time to Crossover; $t_{\text {spall }}$, Time to Deviate from Parabolic; $\mathbf{k}_{\mathrm{p}}$ Estimated from Initial Portion of Curves

\begin{tabular}{|c|c|c|c|c|c|c|}
\hline & $\begin{array}{l}t_{0} \\
h\end{array}$ & $\begin{array}{c}t_{\text {spall }} \\
h\end{array}$ & $\begin{array}{l}\text { transient } \\
\mathrm{mg} / \mathrm{cm}^{2}\end{array}$ & $\begin{array}{c}\text { estimated } \mathrm{K}_{\mathrm{p}} \\
\mathrm{mg}^{2} / \mathrm{cm}^{4} \cdot \mathrm{h}\end{array}$ & $\mathrm{g}^{2} / \mathrm{cm}^{4} \mathrm{~s}$ & $\begin{array}{c}\text { relative } \\
k_{\mathrm{p}} / \mathrm{k}_{\mathrm{p}}, \mathrm{NiAl}\end{array}$ \\
\hline Pt diffused & 90 & 20 & 0.34 & 5.27E-02 & $1.46 \mathrm{E}-11$ & 445 \\
\hline Pure NiAl & 1290 & 460 & 0.14 & $1.18 \mathrm{E}-04$ & $3.29 \mathrm{E}-14$ & 1.0 \\
\hline $\mathrm{Hf}-\mathrm{NiAl}$ & 1770 & 360 & 0.35 & $9.22 \mathrm{E}-04$ & $2.56 \mathrm{E}-13$ & 7.8 \\
\hline Pt-NiAl & 3620 & 500 & 0.53 & 6.33E-04 & $1.76 \mathrm{E}-13$ & 5.3 \\
\hline Hf-Pt-NiAl & 4070 & 520 & 0.24 & 7.12E-04 & $1.98 \mathrm{E}-13$ & 6.0 \\
\hline $\begin{array}{c}\text { MDC150L } \\
\text { (on CMSX4) }\end{array}$ & N.A. & N.A. & 0.10 & $6.50 \mathrm{E}-05$ & $1.81 \mathrm{E}-14$ & 0.5 \\
\hline
\end{tabular}

$400 \mathrm{~h}$. This weight transient was then subtracted, leaving a remainder that could be directly compared to parabolic behavior and estimate the point of deviation.

The specific weight change behavior of all five coatings is shown in Figure 7. Figure 7a presents the entire data set and shows that all coatings exhibit typical cyclic oxidation responses. The time to cross the zero weight axis, $t_{0}$, triggered the end of the test. It can be viewed as an arbitrary, semi-quantitative indication of performance or 'life' and is presented in ascending rank in Table 2. The Pt diffused coating exhibited a rapid high weight gain and loss to zero at $90 \mathrm{~h}$. The simple NiAl aluminide produced a much lower weight gain and crossed zero at $1290 \mathrm{~h}$. The Hf-doped NiAl weights were somewhat higher and lasted until $1770 \mathrm{~h}$. The Pt-doped NiAl and Hf-Pt doped NiAl had similar growth rates, but extended life to 3620 and $4070 \mathrm{~h}$, respectively.

The parabolic growth rate, $k_{p}$, can be analyzed from the slope of isothermal $(\Delta W / A)^{2}$ vs. time or $\Delta W / A$ vs. $t^{1 / 2}$ plots. Transient oxidation effects often result in an intercept at zero time on such "parabolic' plots. Pierragi has analyzed such non-idealities and showed that if the transient scales do not contribute to subsequent rate control for the stable long term oxide, then the $t^{1 / 2}$ construction produces the preferable rate [56]. Conversely, if the transient scale is a transition alumina and does transform to rate controlling $\alpha-\mathrm{Al}_{2} \mathrm{O}_{3}$, then the preferred method employs the $(\Delta \mathrm{W} / \mathrm{A})^{2}$ construction [57]. Both constructions were examined in the present study and it was found that the latter produced substantial deviations from the predicted parabolic curve for the first $100 \mathrm{~h}$, whereas the $\mathrm{t}^{1 / 2}$ construction produced good fits for the majority of the initial $15-400 \mathrm{~h}$ stage of the cyclic curves (Figure $7 \mathbf{b}$ ). These fits were also used to determine a quantity corresponding to the transient oxide by extending the lines to the abscissa at zero time, Table 2.

The parabolic rate constants corresponding to these fits are also listed in Table 2, in both practical $\mathrm{mg}^{2} / \mathrm{cm}^{4} \mathrm{~h}$ and $\mathrm{g}^{2} / \mathrm{cm}^{4} \mathrm{~s}$ units. It is seen that the Pt-diffused coating is over two orders of magnitude higher than that for the simple aluminide. The Pt-, Hf-, and Hf-Pt-doped aluminides are all similar and about 5-8 times that of the simple aluminide. And the commercial
Howmet MDC150L Pt-NiAl is roughly half that of the simple aluminide.

Next the raw experimental data was modified by subtracting the transient amount determined above and re-plotted along with idealized curves projected from the corresponding parabolic rates, Figure 7c. This allows for a more critical analysis of the kinetic behavior and shows that the cyclic and parabolic behavior of the aluminide coatings coincides for about the first 350-500 h. The deviation between corresponding cyclic and isothermal curves can be estimated visually and suggests where spallation may become significant. This value, referred to as $t_{\text {spall }}$, is presented as solid symbols on each curve and is listed in Table 2 . It can be seen that while the Hf-NiAl coating deviates before the simple aluminide, it exhibits a shallower rate of final weight loss in Figure 7a. Both the Pt-NiAl and Hf-Pt-NiAl coatings have the largest $t_{\text {spall }}$ and $t_{0}$ and show similar behavior for the entire curve. The issues raised above will be significant in light of various mechanisms and the microstructural features discussed below.

\subsection{Overall Characterization}

\subsubsection{Optical Appearance}

The general surface appearance is shown in the optical micrographs of Figure 8. After 100h the Pt-diffused coating was fully covered with a duplex oxide, with remnants or flakes of an outer scale layer that spalled off (Figure 8a). The simple NiAl coating after 1500 h, Figure 8b, exhibited jigsaw morphology of bright reflective areas, a light grey oxide, and a medium tan-ochre oxide. The characteristic dimension was on the order of $25 \mu \mathrm{m}$, or similar to the $20-40 \mu \mathrm{m}$ prior grain size of the coating. The same was true for the Pt-NiAl coating after $4070 \mathrm{~h}$, Figure $\mathbf{8 d}$, but with more area of exposed metal, more area of uniform light grey scale, and a distinctive network pattern. Here the characteristic dimension was 20 $\mu \mathrm{m}$, compared to that of the original $5-10 \mu \mathrm{m}$ of the surface cusps. However, the Hf-NiAl coating shown after $2000 \mathrm{~h}$ in Figure 8c, possessed features that were $\sim 100-200 \mu \mathrm{m}$, more uniformly distributed, and not reflective of the prior 10-20 $\mu \mathrm{m}$ coating grain boundary network. Lastly, the same description 
$1050^{\circ} \mathrm{C}$ Oxidation of Sifco NiAl (Pt,Hf) on IN-718

Cyclic Furnace Test, $20 \mathrm{hr} /$ cycle

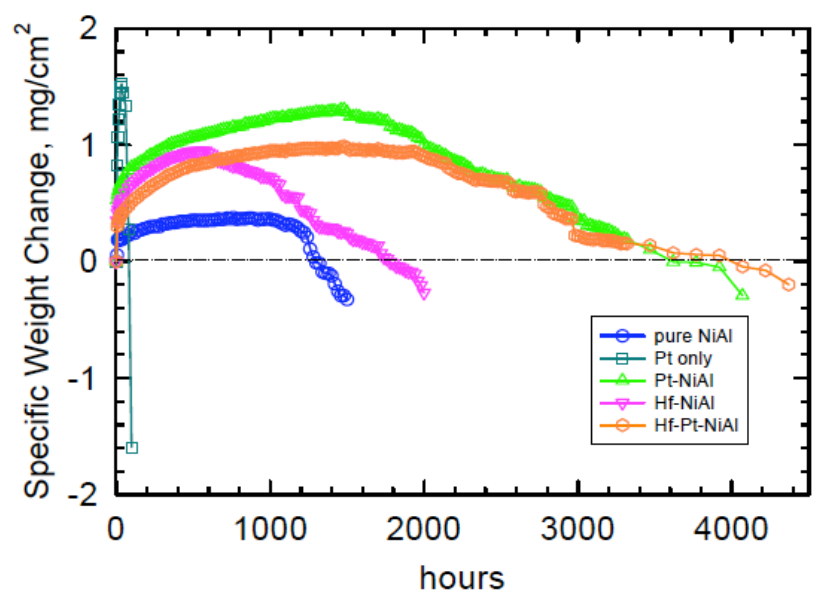

(a) $1050^{\circ} \mathrm{C}$ Oxidation of Sifco NiAl (Pt,Hf) on IN-718

Cyclic Furnace Test, $20 \mathrm{hr} /$ cycle

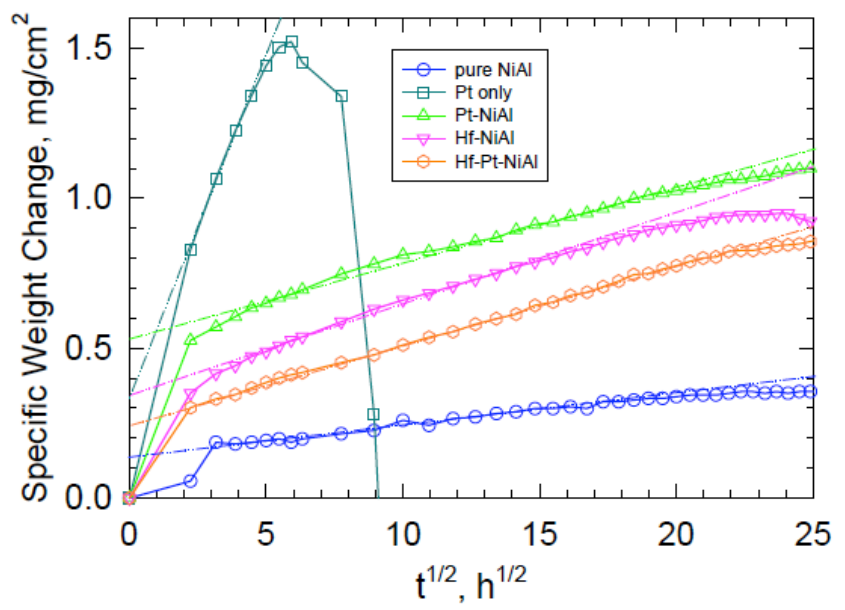

(b)

$1050^{\circ} \mathrm{C}$ Oxidation of Sifco NiAl (Pt,Hf) on IN-718

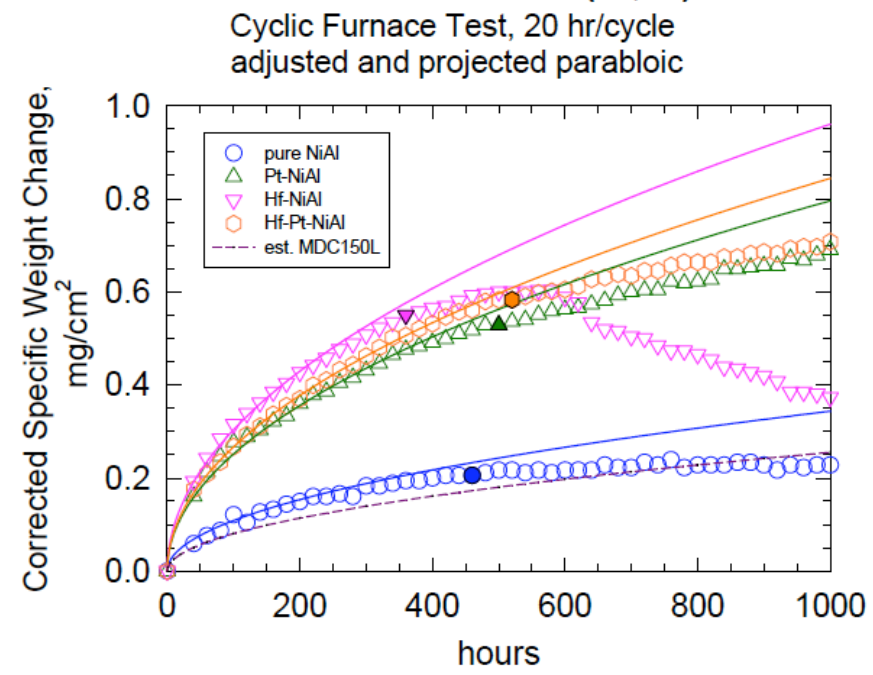

(c)

Figure 7: $1050^{\circ} \mathrm{C}$ cyclic oxidation weight change behavior of coatings on Inconel 718 .

a) Specific weight change vs time; b) Specific weight change vs $t^{1 / 2}$ parabolic plots; c) Transient-corrected cyclic curves (open symbols) compared to parabolic projections (no symbols); solid points indicate deviation of cyclic and isothermal curves.

applies to the Hf-Pt-NiAl coating shown after $4370 \mathrm{~h}$ in Figure $8 \mathrm{e}$.

\subsubsection{X-Ray Diffraction Results}

The surfaces of the oxidized samples were analyzed by X-ray diffractometer scans after the tests were completed. The resulting metal and scale phases are listed in Table 3. The numerical values are semi-quantitative estimates of the relative wt. \% of the surface phases, using a commercial software program and assuming a uniform distribution and random crystallographic orientations. All the samples revealed a considerable amount of metal phase, as exposed by spalling or detected under the scale thickness. These were characterized as $\gamma-\mathrm{Ni}_{\text {soln }}$. and/or $\gamma^{\prime}-\mathrm{Ni}_{3} \mathrm{Al}$, with some ambiguity because of the weakness of the discerning superlattice peak and its overlap with peaks from the rhombohedral corundum structures. The quantity of metal phase decreased with coatings ordered by increasing time to reach zero weight gain. This is consistent with thicker scales and absorption as well as less area of bare metal exposed by spalling.

The Pt diffused coating produced primarily $\alpha-\mathrm{Cr}_{2} \mathrm{O}_{3}$ and $\mathrm{TiNbO}_{4}$ rutile scales, in nearly equal amounts. The other coatings produced primarily $\alpha-\mathrm{Al}_{2} \mathrm{O}_{3}$ scales, with minor amounts of $\mathrm{Ni}(\mathrm{Al}, \mathrm{Cr})_{2} \mathrm{O}_{4}$ spinel and variations of $\mathrm{TiO}_{2}$ or $\mathrm{CrNbO}_{4}$ rutile structures. The observed d-spacings of the spinel solid solution phases are listed, considering that those of $\mathrm{NiAl}_{2} \mathrm{O}_{4}$ and $\mathrm{NiCr}_{2} \mathrm{O}_{4}$ are $8.05 \mathrm{~A}^{\circ}$ and $8.35 \mathrm{~A}^{\circ}$, respectively. Similarly, the a and $c$ lattice parameters of the rutile phases 


\section{Pt diffused, $100 \mathrm{~h}, 50 \mathrm{x}$}

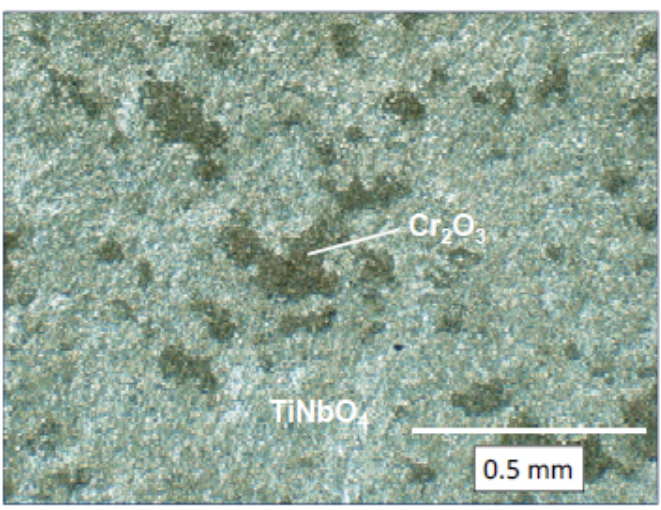

(a)

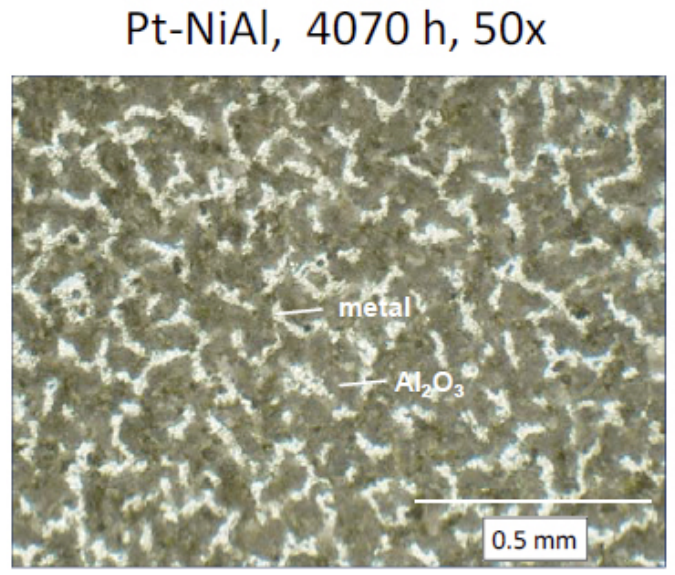

(c)

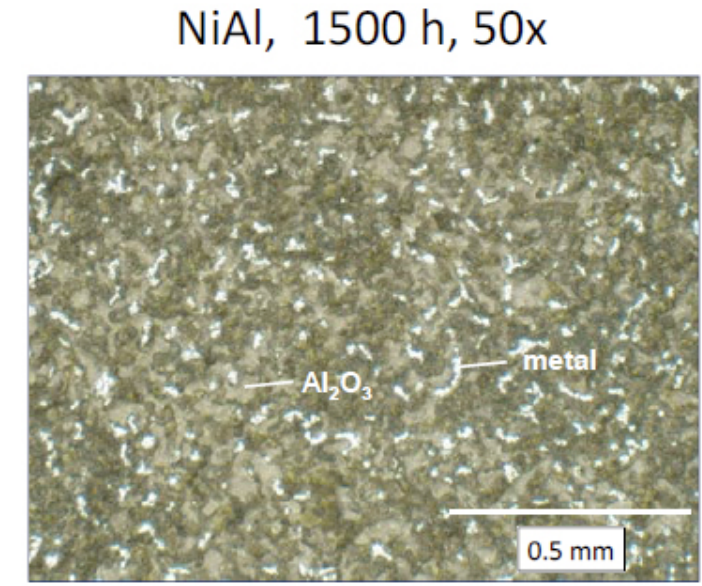

(b)

Hf-NiAl, 2000 h, 50x

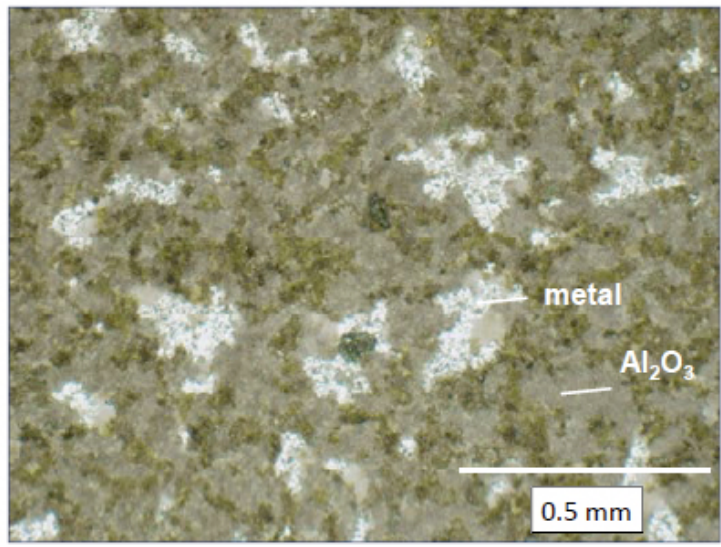

(d)

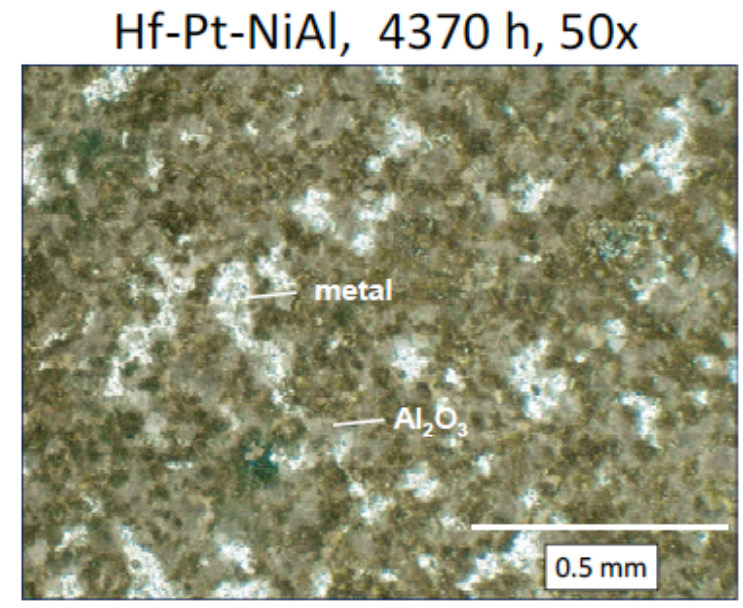

(e)

Figure 8: General coating surface and scale appearance at the end of $1050^{\circ} \mathrm{C}$ cyclic oxidation tests. (low magnification optical micrographs;). a) Pt-diffused coating, 100 h; b) Simple NiAl, 1500 h; c) Hf-NiAl, 2000 h; d) Pt-NiAl, 4070 h, e) Hf-Pt-NiAl, 4370 h.

may vary over $\mathrm{Ti}, \mathrm{Nb}, \mathrm{Cr}$, Ni solid solutions, where those of $\mathrm{TiNbO}_{4}$ are $4.72 \AA$ and $3.00 \AA$, respectively.

\subsubsection{Coating Composition}

This topic will be addressed below, but it is helpful to first point out some overall trends. The EDS characterization of the coating composition is summarized before and after testing in Table 1. It is seen that all the aluminide coatings exhibit a dramatic drop in Al content, decreasing from 30 wt.\% initially down to as low as 2 wt.\%, while increasing in $\mathrm{Nb}$ content from zero to $\sim 5 \mathrm{wt} \%$. The three $\mathrm{Pt}$ and $\mathrm{Hf}$ doped aluminides also exhibited $\sim 15 \mathrm{wt}$. \% $\mathrm{Cr}$ and $\mathrm{Fe}$ at the end of 
Table 3: Surface Phase Content of Coatings on Inconel 718 after Cyclic Oxidation at $1050^{\circ} \mathrm{C}$. (wt. \%, Semi-Quantitative). Spinels and Rutiles may have Various Compositions that Produce the Same Lattice Parameters

\begin{tabular}{|c|c|c|c|c|c|c|c|c|c|c|c|}
\hline $\begin{array}{l}1050^{\circ} \mathrm{C} \\
\text { coating }\end{array}$ & $\begin{array}{l}\text { time } \\
\text { hours }\end{array}$ & $\begin{array}{l}\text { weight } \\
\mathrm{mg} / \mathrm{cm}^{2}\end{array}$ & $\begin{array}{c}\text { metal } \\
\gamma / \gamma^{\prime}\end{array}$ & $\begin{array}{l}\text { alumina } \\
\alpha-\mathrm{Al}_{2} \mathrm{O}_{3}\end{array}$ & $\begin{array}{l}\text { chromia } \\
\alpha-\mathrm{Cr}_{2} \mathrm{O}_{3} \\
\end{array}$ & & rel $)_{2} \mathrm{O}_{4}$ & $\mathrm{Ti}(\mathrm{Nb}) \mathrm{O}_{4}$ & $\begin{array}{r}\text { rutile } \\
\mathrm{TiNbO}_{4} \\
\end{array}$ & $\mathrm{CrNbO}_{4}$ & $\mathrm{HfO}_{2}$ \\
\hline Pt diffused & 100 & -1.59 & 32 & & 35 & & & 3 & 30 & & \\
\hline $\mathrm{NiAl}$ & 1500 & -0.33 & 51 & 45 & & 2 & 8.17 & 2 & & & \\
\hline $\mathrm{Hf}-\mathrm{NiAl}$ & 2000 & -0.27 & 38 & 54 & & 2 & 8.15 & & & 2 & 3 \\
\hline Pt-NiAl & 4070 & -0.29 & 32 & 66 & & 2 & 8.15 & & & 1 & \\
\hline Hf-Pt-NiAl & 4370 & -0.20 & 24 & 63 & & 9 & 8.12 & 3 & & & 2 \\
\hline
\end{tabular}

testing. These changes may be responsible for significant effects on oxidation.

\subsection{Detailed SEM/EDS Characterization}

SEM/EDS studies of the oxidized surface were made at 100 , $500,1500,2000,2560,4070$, and $4370 \mathrm{~h}$, depending on the particular coating and whether it survived that long. The series presented below used primarily backscatter imaging (BSE) for discrimination by atomic weight.

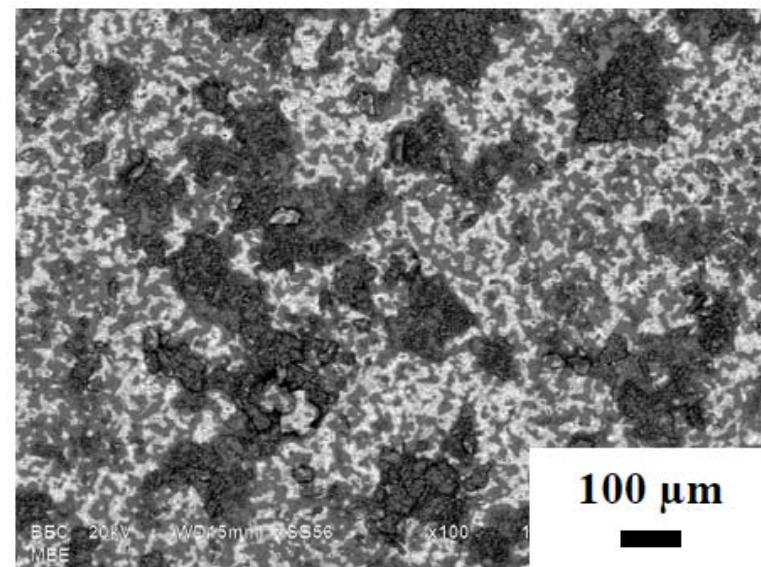

(a)

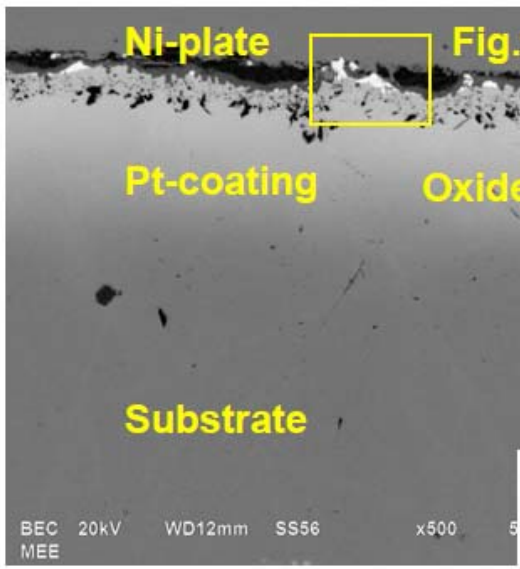

(c)

\subsubsection{Pt-Diffused Coating}

Exposure of the Pt coated specimen was stopped after $100 \mathrm{~h}$ testing. The weight change had already gone through its maximum, crossed zero, and achieved a loss of $\sim 1.5 \mathrm{mg} / \mathrm{cm}^{2}$. The microstructure of the oxidized specimen surface in Figures $9 a$ and $9 \mathbf{b}$ shows an intertwined mixture of dark and light phases, but perhaps at a different area ratio than the features in Figure 8a. Three different areas are indicated by contrast and EDS: the dark area ("A" in Figure 9b) was chromium oxide, expected to be $\alpha-\mathrm{Cr}_{2} \mathrm{O}_{3}$; the gray area (" $\mathrm{B}$ "

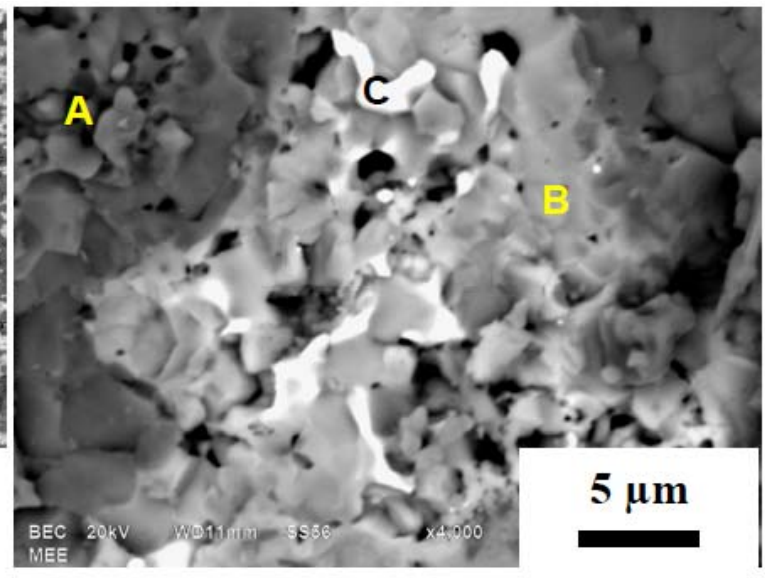

(b)

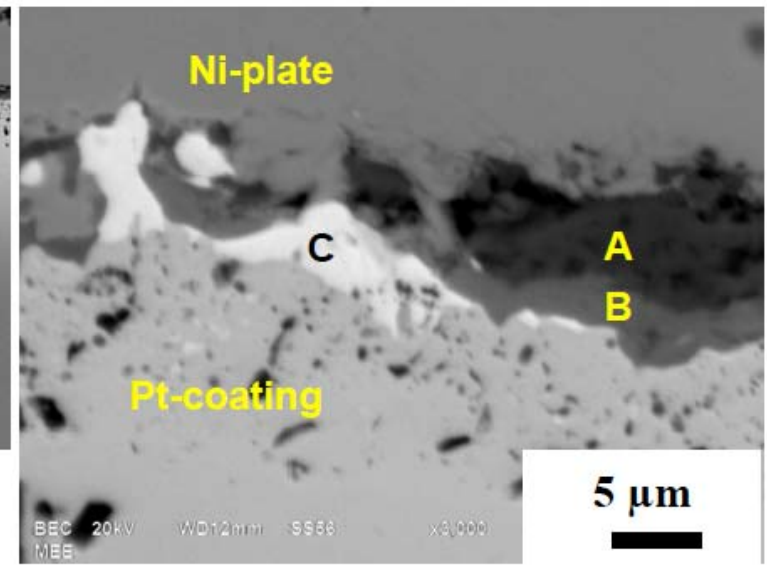

(d)

Figure 9: SEM backscattered electron micrographs of the Pt-diffused coating after $100 \mathrm{~h}$ oxidation at $1050^{\circ} \mathrm{C}$. (a) and (b) Surface morphology, (c) and (d) Cross-section. 
in Figure 9b) was niobium-rich oxide (a form of the $(\mathrm{Ti}, \mathrm{Cr}) \mathrm{NbO}_{4}$ rutiles); and the brightest phase ("C" in Figure 9b) was Pt-rich metal. Similarly, the scale exhibited three regions in cross-section (Figures $9 \mathrm{c}$ and $9 \mathrm{~d}$ ): the outer dark area, "A", the gray area, "B", and the bright phase, $\mathrm{C}$, were chromium oxide, niobium-rich oxide, and Pt-rich phases, respectively, consistent with the surface structure. The chromium oxide layer thus appears to be an outer layer that has spalled in many areas. It was also found that the initial $\mathrm{Pt}$ layer diffused an additional $\sim 25 \mu \mathrm{m}$ into the alloy.

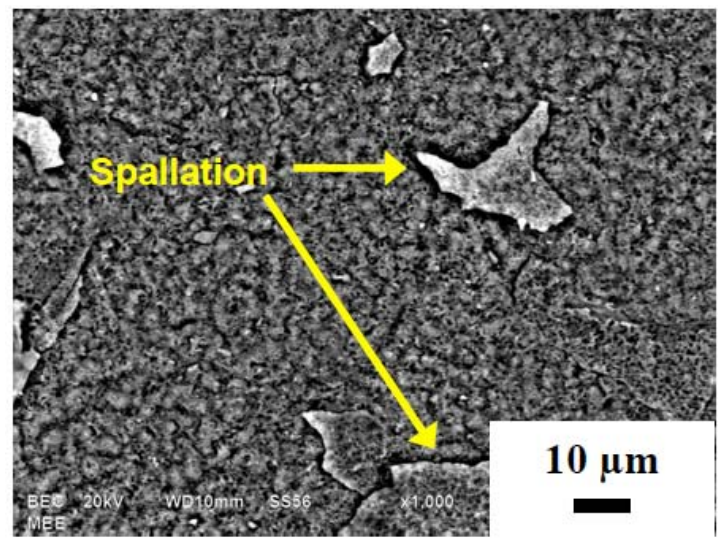

(a)

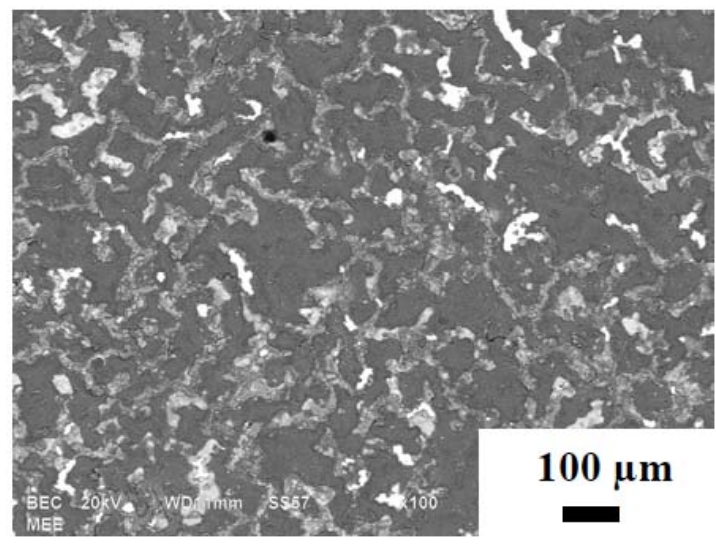

(c)

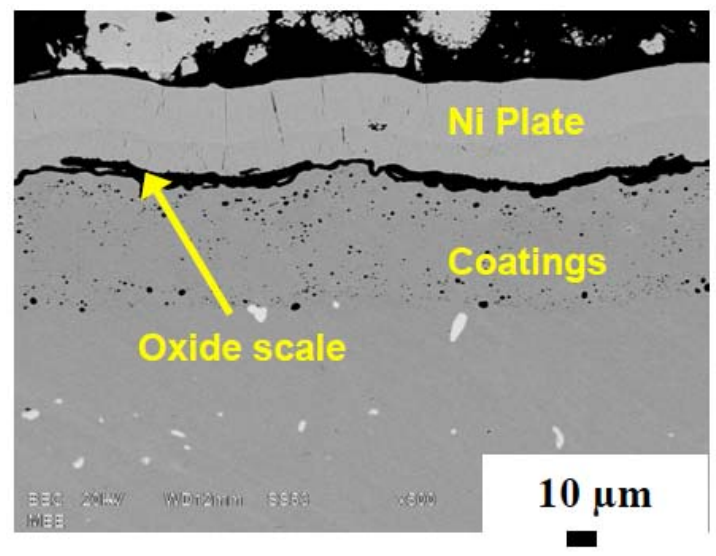

(e)

\subsubsection{NiAl Coating}

The NiAl-coated specimen was inspected by SEM/EDS at $100 \mathrm{~h}, 500 \mathrm{~h}$, and $1500 \mathrm{~h}$, at which point the test was stopped, Figure 10. After $100 \mathrm{~h}$ oxidation, an Al-rich oxide, presumably $\alpha-\mathrm{Al}_{2} \mathrm{O}_{3}$, was present with cracks and spalled flakes (Figure 10a). Local scale spallation, found in one corner, was analyzed to be rich in $\mathrm{Ni}, \mathrm{Cr}, \mathrm{Nb}$, etc., with no oxygen, indicating exposed metal. After $500 \mathrm{~h}$, the $\mathrm{Al}_{2} \mathrm{O}_{3}$ scale remained mostly adherent, but spalled flakes and cracks in

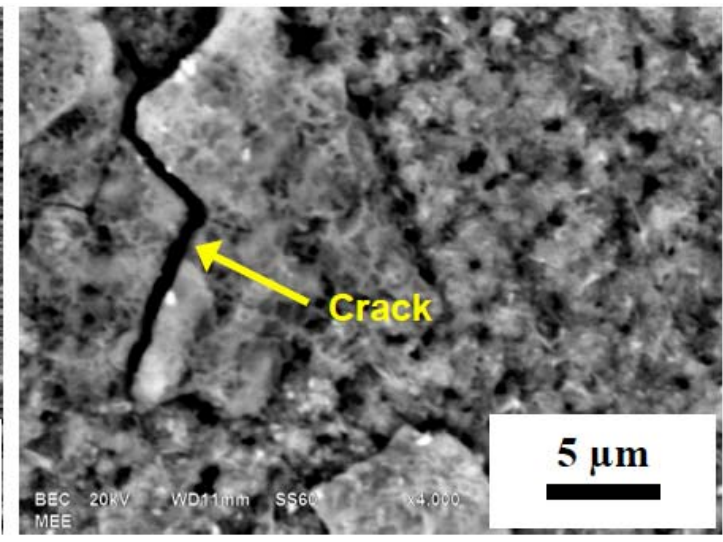

(b)

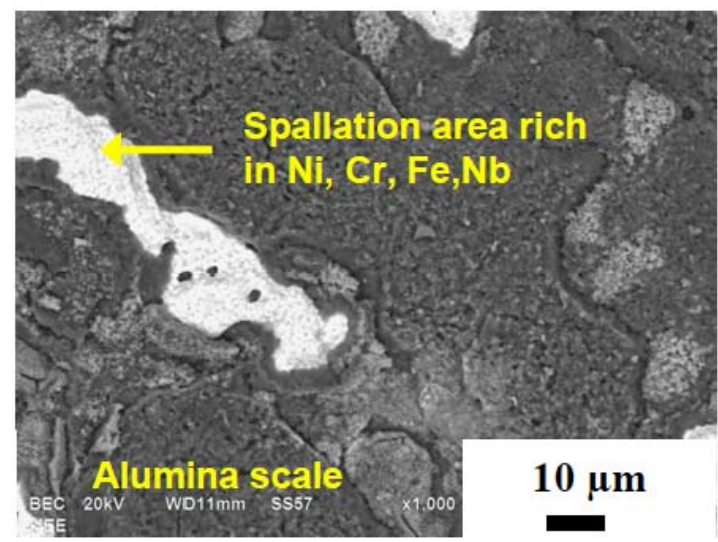

(d)

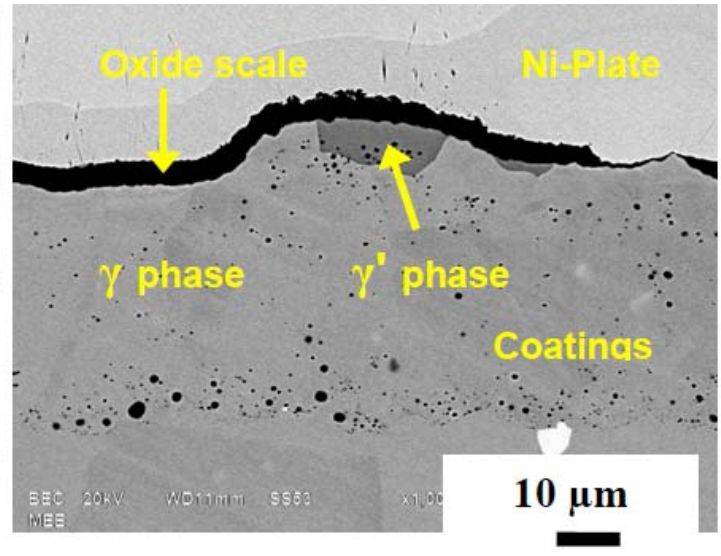

(f)

Figure 10: SEM of the simple NiAl coating oxidized at $1050^{\circ} \mathrm{C}$. Surface morphology (a) after $100 \mathrm{~h}$, (b) after $500 \mathrm{~h},(\mathbf{c})$ and (d) after $1500 \mathrm{~h}$ testing, and cross-section (e) and (f) after $1500 \mathrm{~h}$. 


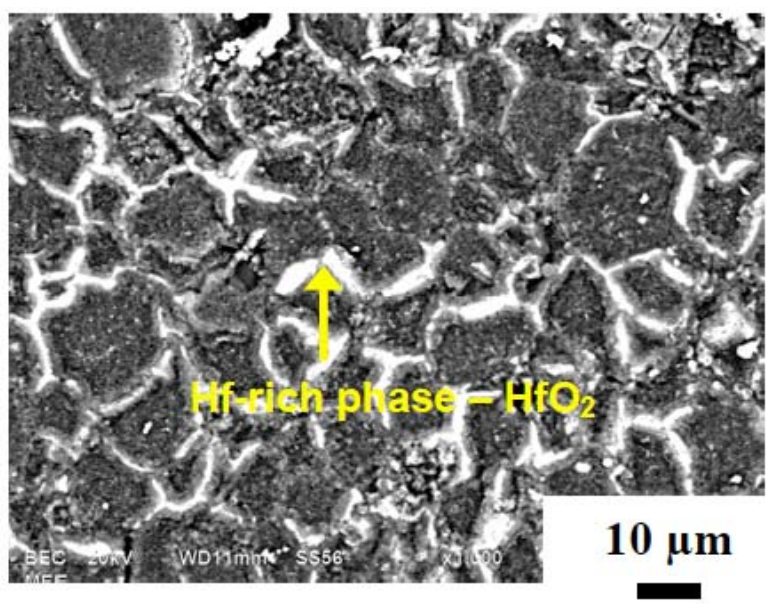

(a)

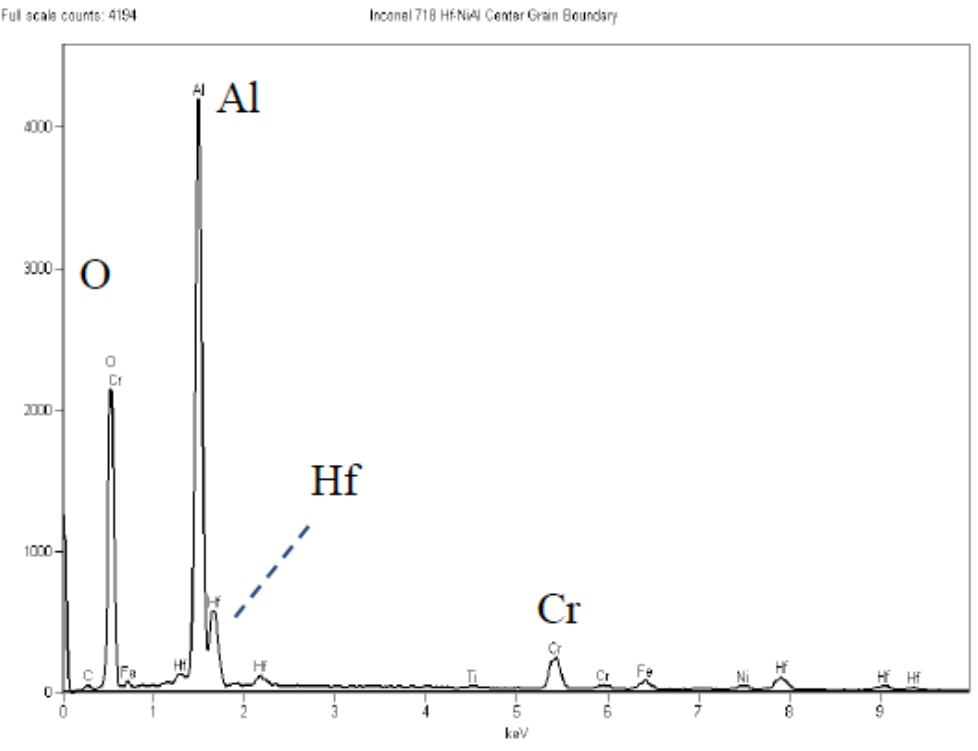

(b)

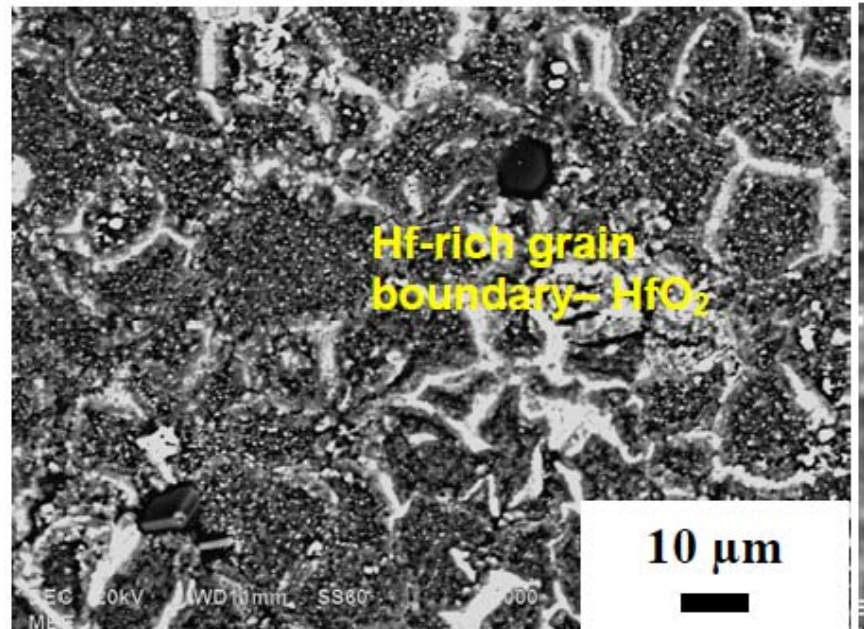

(c)

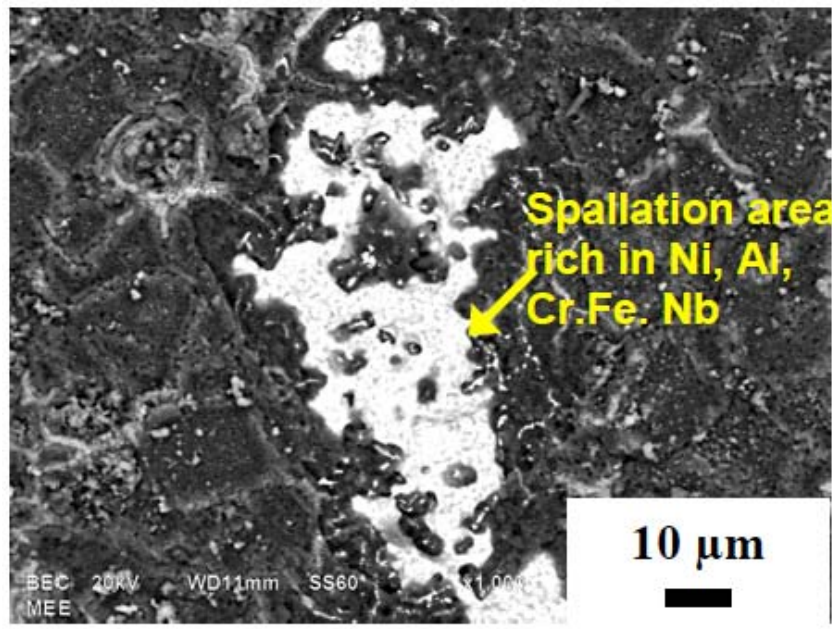

(e)

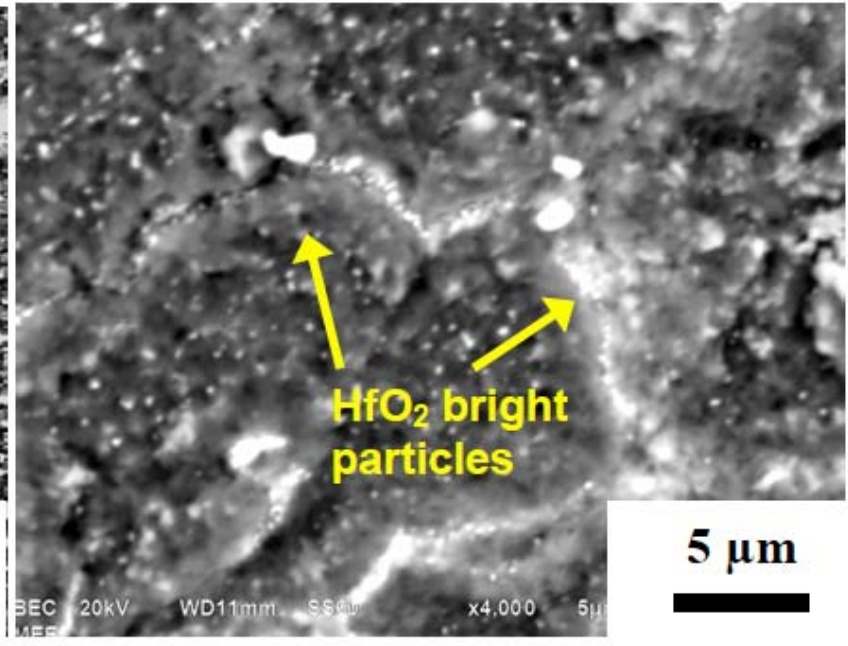

(d)

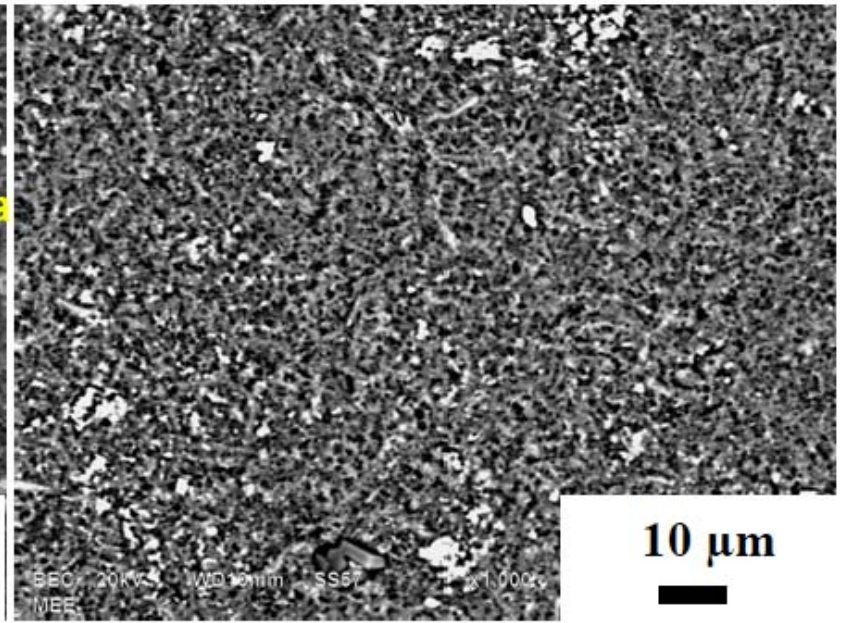

(f) 
(Figure 11). Continued.

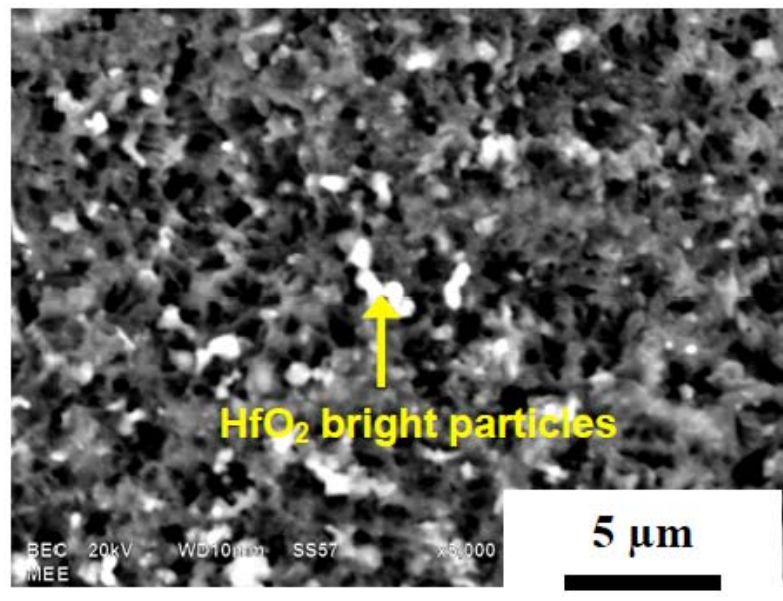

$(\mathbf{g})$

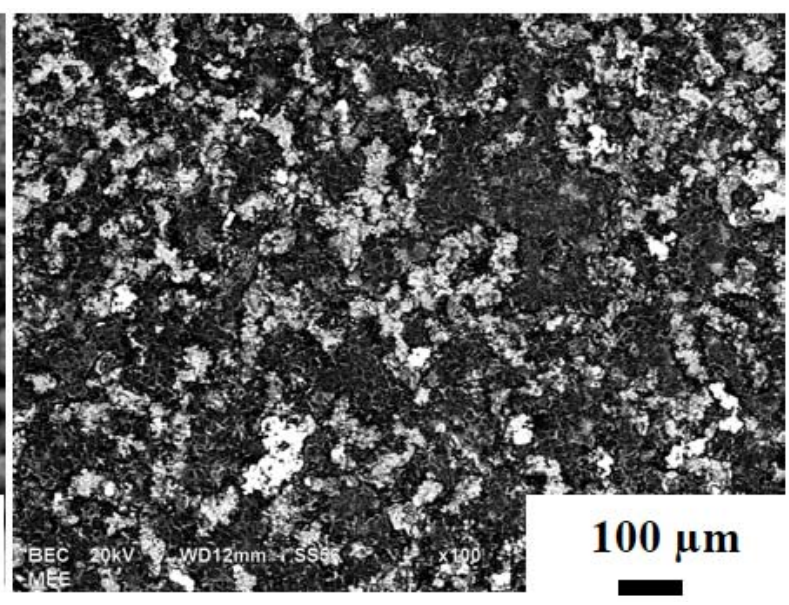

(h)

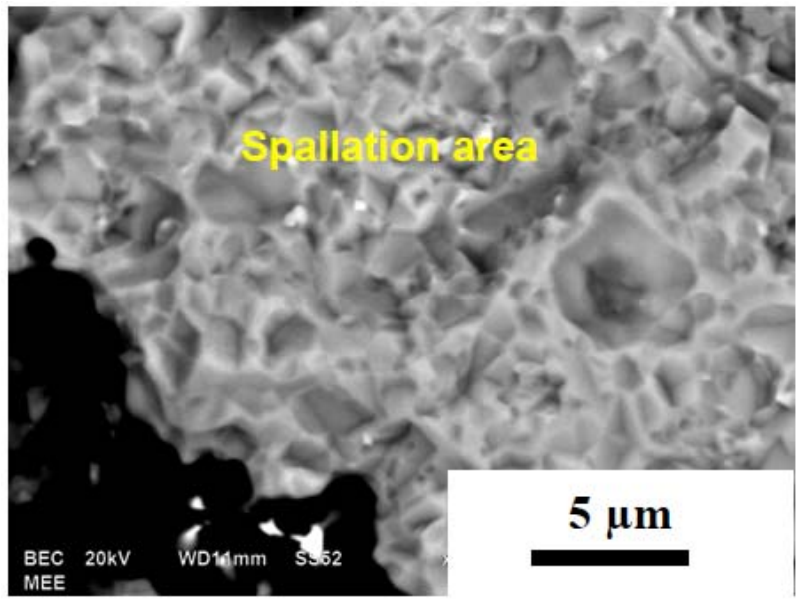

(i)

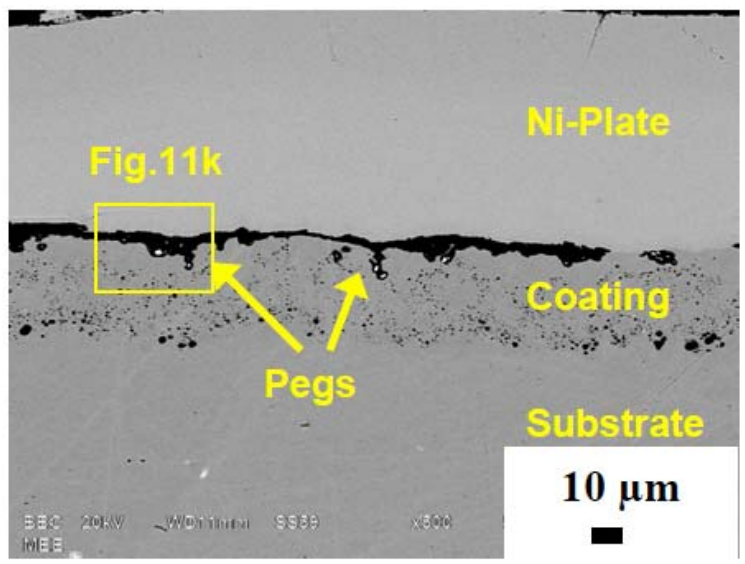

(j)

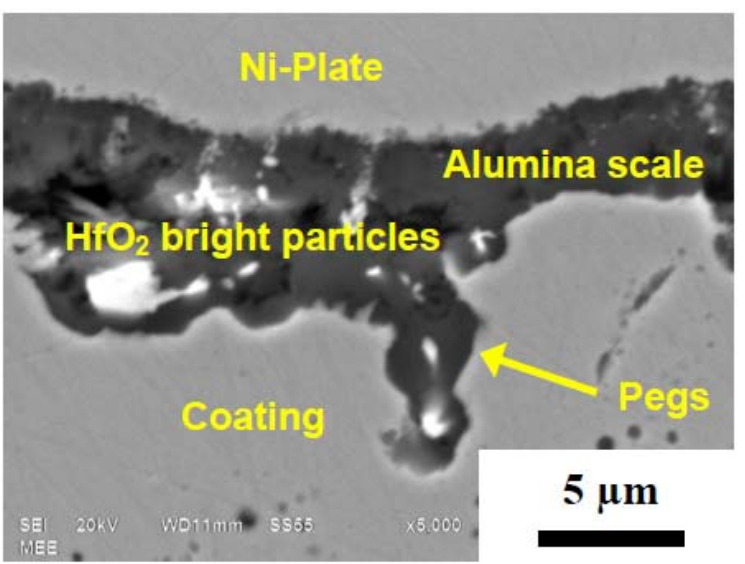

(k)

Figure 11: SEM backscattered electron micrographs of the Hf-NiAl coating oxidized at $1050^{\circ} \mathrm{C}$. Surface (a) after 100h; (b) EDS spectrum obtained from a grain boundary; (c) (d), and (e) after 500h; (f) and (g) after 1500h; (h) and (i) after 2000h; and cross-section (j) and (k) after $2000 \mathrm{~h}$.

the retained scale were again found (Figure 10b). This is consistent with deviation from the predicted isothermal behavior occurring at $\sim 460 \mathrm{~h}$. Finally, after $1500 \mathrm{~h}$ exposure, an extensive 'river' network of bright, exposed metal spalled areas and grey oxide was apparent (Figures 10c and 10d).
The bright metal areas were again rich in $\mathrm{Ni}, \mathrm{Cr}$, and $\mathrm{Nb}$, with no oxygen. The grey phases were rich in $\mathrm{Ni}, \mathrm{Al}, \mathrm{Cr}$, and $\mathrm{O}$, presumably $\mathrm{Ni}(\mathrm{Al}, \mathrm{Cr})_{2} \mathrm{O}_{4}$ spinel. The dark circumscribed islands were remnant $\mathrm{Al}$-oxide. The bare metal appeared more as a uniform dispersed phase in the final optical 
micrograph, Figure $\mathbf{8 b}$. But here it is seen associated with the spinel scale in an associated network pattern. It can be surmised that the spinel network represents re-oxidized bare metal from prior cycles, and that both together portray a pattern where spalling was preferred, perhaps associated with the rumpling patterns. The weight change at this time was a loss of $0.3 \mathrm{mg} / \mathrm{cm}^{2}$.

Surface undulations or rumpling were clearly seen in the NiAl cross-section (Figures $\mathbf{1 0 e}, \mathbf{f}$ ). In addition, islands of a gray phase (Figure 10f) were formed in the coating just below the $\mathrm{Al}_{2} \mathrm{O}_{3}$ scale. The island was analyzed by EDS to be $67.5 \mathrm{Ni}-$ 16.8Al-5.1Cr-8.0Fe-1.0Ti-1.6Nb (wt. \%), indicating the $\mathrm{Y}^{\prime}-$ $\mathrm{Ni}_{3} \mathrm{Al}$ phase, while the surrounding matrix was $72.9 \mathrm{Ni}-8.2 \mathrm{Al}$ $3.2 \mathrm{Cr}-6.6 \mathrm{Fe}-2.2 \mathrm{Ti}-6.9 \mathrm{Nb}$, indicating $\mathrm{y}-\mathrm{Ni}$ solid solution. Both are consistent with $\mathrm{XRD}$ results. The transformation from the original $\beta$-NiAl into $\gamma^{\prime}-\mathrm{Ni}_{3} \mathrm{Al}$ and $\mathrm{Y}-\mathrm{Ni}$ was caused by $\mathrm{Al}$ depletion due to the formation and spallation of $\mathrm{Al}_{2} \mathrm{O}_{3}$ scales and interdiffusion with the substrate.

\subsubsection{Hf-NiAl Coating}

The Hf-NiAl coated specimen was examined by SEM/EDS at $100 \mathrm{~h}, 500 \mathrm{~h}, 1500 \mathrm{~h}$, and $2000 \mathrm{~h}$ exposures, at which point testing was halted. At $100 \mathrm{~h}$, the dense base scale was primarily $\mathrm{Al}_{2} \mathrm{O}_{3}$, while the $\mathrm{Hf}$-rich coating grain boundaries were highly delineated (Figure 11a, b). The bright ridges and the small $\mathrm{Hf}$-rich bright particles are expected to be $\mathrm{HfO}_{2}$ [39], as shown by XRD. This would be consistent with results for $\mathrm{Hf}$-doped bulk NiAl, where $\mathrm{HfO}_{2}$ particles are observed to grow at the outer surface of $\mathrm{Al}_{2} \mathrm{O}_{3}$ [29]. After $500 \mathrm{~h}$, the $\mathrm{Al}_{2} \mathrm{O}_{3}$ scales remained adherent for the most part (Figure 11c), again with $\mathrm{HfO}_{2}$ bright particles decorating the coating grain boundaries (Figure 11d). However, some localized spallation was found in the corner area of the specimen (Figure 11e). This is consistent with deviation from the predicted isothermal curve occurring earlier at $\sim 360 \mathrm{~h}$. The spalled region was rich in $\mathrm{Ni}, \mathrm{Al}, \mathrm{Cr}, \mathrm{Fe}, \mathrm{Nb}$, but no oxygen, indicating metal exposed by interfacial alumina scale spallation.

After $1500 \mathrm{~h}$, the weight change was well past the maximum of $0.9 \mathrm{mg} / \mathrm{cm}^{2}$ at $\sim 600 \mathrm{~h}$, falling to $0.2 \mathrm{mg} / \mathrm{cm}^{2}$ and tending toward zero weight change. Spallation continued at corner areas, but the scale was still adherent in most areas, Figure 11f. Finely dispersed, bright $\mathrm{HfO}_{2}$ particles, Figure 11g, were also present, yet the pattern of coating grain boundary decoration was supplanted by a more uniform distribution of features. Coupled with weight loss, this suggests that interfacial spallation occurred at least once over the entire sample, leaving an altered, re-healed structure with no evidence of the original scale. After 2000h exposure, the surface structure showed a dispersed mixture of intact $\alpha$ $\mathrm{Al}_{2} \mathrm{O}_{3}$, spallation, and bright $\mathrm{HfO}_{2}$ particles, Figure $11 \mathrm{~h}$, consistent with XRD results. The $\mathrm{HfO}_{2}$ particles were estimated to be less than 100 nanometers in diameter. The spallation area exhibited the characteristic imprints of the spalled $\alpha-\mathrm{Al}_{2} \mathrm{O}_{3}$ grains (Figure 11i) and was rich in $\mathrm{Ni}, \mathrm{Cr}, \mathrm{Fe}$, $\mathrm{Al}, \mathrm{Nb}$ and $\mathrm{Mo}$, with no oxygen. The overall spalling distribution was resolved more clearly in the optical micrograph of Figure $\mathbf{8 e}$, showing there a uniform distribution of $100-200 \mu \mathrm{m}$ patches of spalled regions. At this point the coating had reached $-0.3 \mathrm{mg} / \mathrm{cm}^{2}$.

The polished cross-section (Figure 11j) showed less surface rumpling compared with the failed NiAl coat. The coating composition, Table 1, was $55.1 \mathrm{Ni}-2.6 \mathrm{Al}-16.5 \mathrm{Cr}-17.1 \mathrm{Fe}-1.1 \mathrm{Ti}-$ $5.0 \mathrm{Nb}-2.6 \mathrm{Mo}$ (wt. \%), indicating that the initial $\beta$-NiAl phase had completely transformed into $\mathrm{Y}-\mathrm{Ni}_{\text {soln }}$, as indicated by XRD. $\mathrm{Cr}, \mathrm{Fe}$, and $\mathrm{Nb}$ content increased considerably. Oxide pegs were observed, and their morphology at high magnification, Figure 11k, indicates bright $\mathrm{HfO}_{2}$ particles surrounded by $\mathrm{Al}_{2} \mathrm{O}_{3}$. The size of the $\mathrm{HfO}_{2}$ particles varied from less than 100 nanometers to several micrometers ( 2.5 $\mu \mathrm{m}$ max.).

\subsubsection{Pt-NiAl Coating}

The exposure of the Pt-NiAl coat specimen was inspected at $100 \mathrm{~h}, 500 \mathrm{~h}, 1500 \mathrm{~h}, 2560 \mathrm{~h}$, and after stopping at $4070 \mathrm{~h}$ exposures. At $100 \mathrm{~h}$, the dense $\mathrm{Al}_{2} \mathrm{O}_{3}$ oxide scale reflected the cusped, ridge structure of the coating and exhibited no spallation (Figure 12a). The fine bright particles along these ridges were rich in $\mathrm{Nb}$, presumably as $\mathrm{Nb}$-containing rutile embedded in alumina. After $500 \mathrm{~h}$, the same ridge features were seen except that the size of the bright $\mathrm{Nb}$-rich particles increased, (Figure 12b). At 1500h, a large number of cracks were formed in the alumina scale (Figure 12c), but with no apparent spallation. Even though the weight change had begun to deviate from projected isothermal response at 500 $\mathrm{h}$, it was still gaining weight up to $1470 \mathrm{~h}$. At 2560h, significant spallation had occurred (Figure 12d), leading to a loss of about $1 / 2$ the maximum gained. The spalled regions again showed the typical polygonal alumina grain imprint structure in exposed metal, rich in $\mathrm{Ni}, \mathrm{Al}, \mathrm{Nb}, \mathrm{Pt}, \mathrm{Cr}$, and $\mathrm{Fe}$, with no oxygen. After $4070 \mathrm{~h}$, the scale surface showed more spallation (Figure 12e), and alumina scales decorated with bright $\mathrm{Nb}$-rich oxide particles (Figure 12f). Other light grey areas starting at $1500 \mathrm{~h}$ and seen increasingly here appeared to be previously spalled and re-healed areas, showing an Al, $\mathrm{Ni}, \mathrm{Cr}$-rich scale, presumably $\mathrm{Ni}(\mathrm{Al}, \mathrm{Cr})_{2} \mathrm{O}_{4}$ spinel. These results reflect the XRD identification of $\alpha-\mathrm{Al}_{2} \mathrm{O}_{3}$, spinel, and $\mathrm{CrNbO}_{4}$ rutile. However, it estimated a lower quantity of spinel and more $\mathrm{Cr}$ in the rutile than expected.

In the low magnification optical micrograph, Figure 8d, it was seen that the spalled regions formed a distinctive but disconnected pattern with perhaps some relationship to the highly cusped network of the original coating structure. But, interestingly, the spalled features here exhibit a characteristic dimension and spacing that is $\sim 200 \mu \mathrm{m}$ or many times greater than that of the $\sim 5 \mu \mathrm{m}$ coating cusp features. They may thus correspond to a rumpling dimension, with outlines somewhat defined by the fine cusp features.

In cross-section, the oxidized surface showed significant rumpling (Figure $\mathbf{1 2 g}$, with the fine $\mathrm{Nb}$-rich oxide bright particles embedded in the alumina layer (Figure 12h). The Pt- 


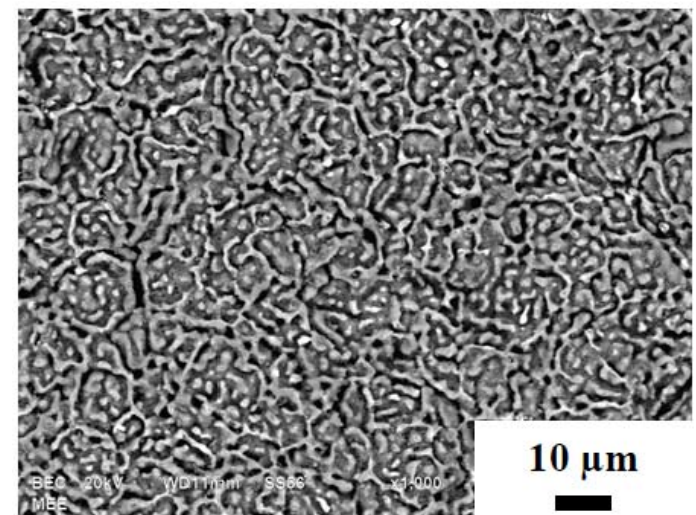

(a)

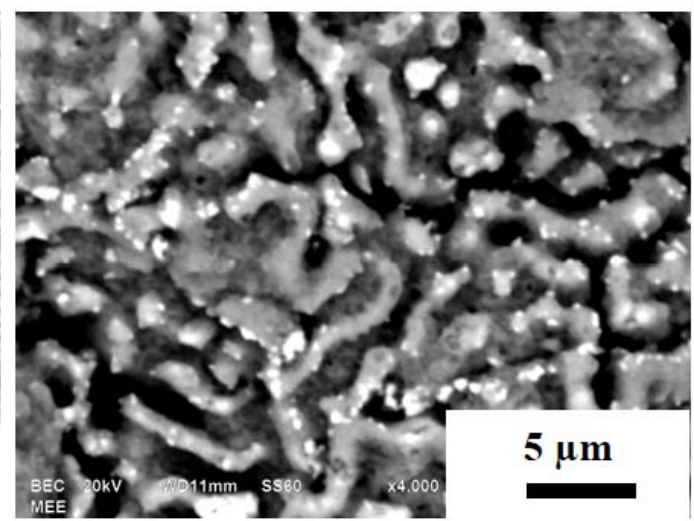

(b)

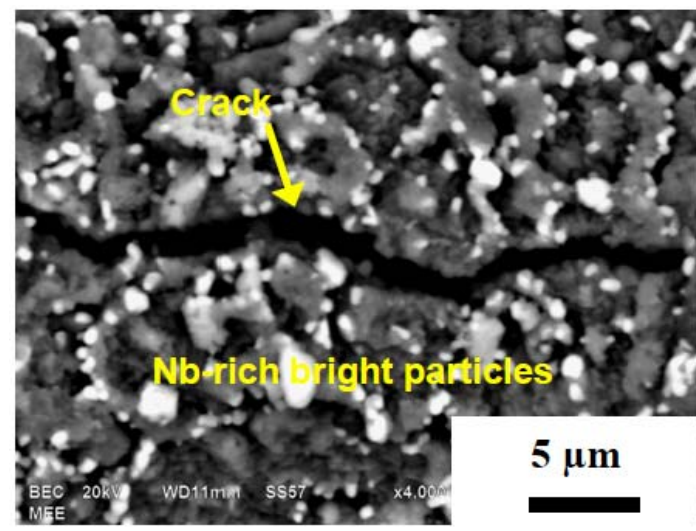

(c)

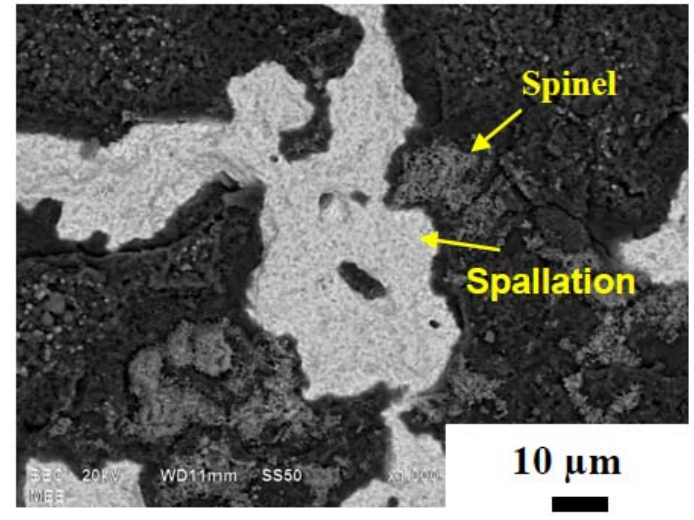

(e)

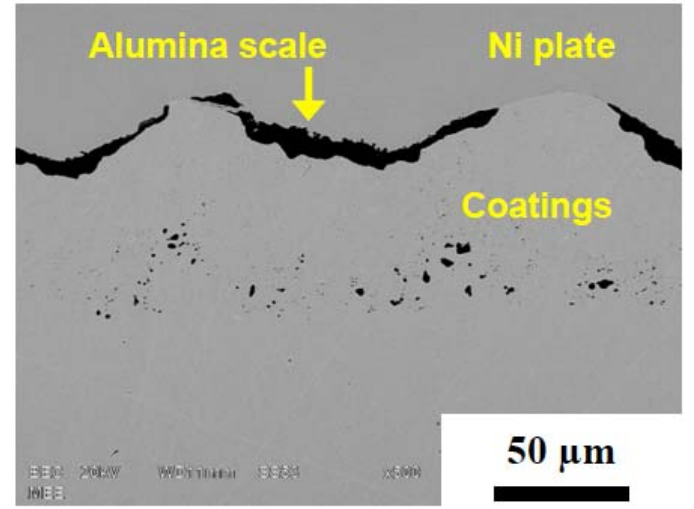

$(\mathbf{g})$

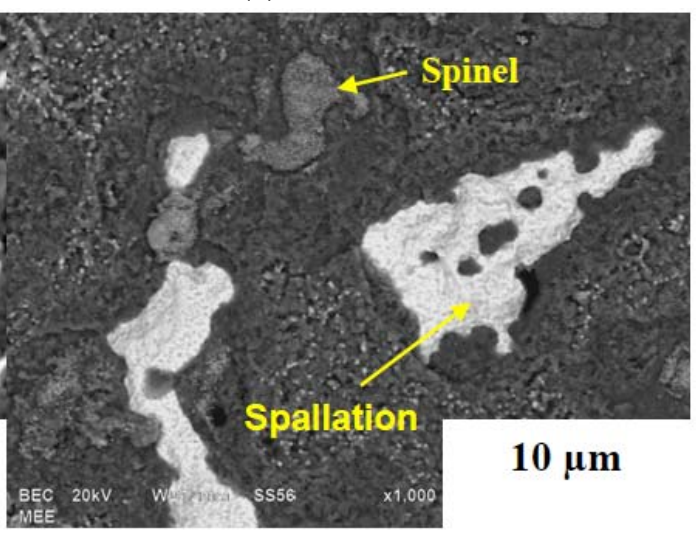

(d)

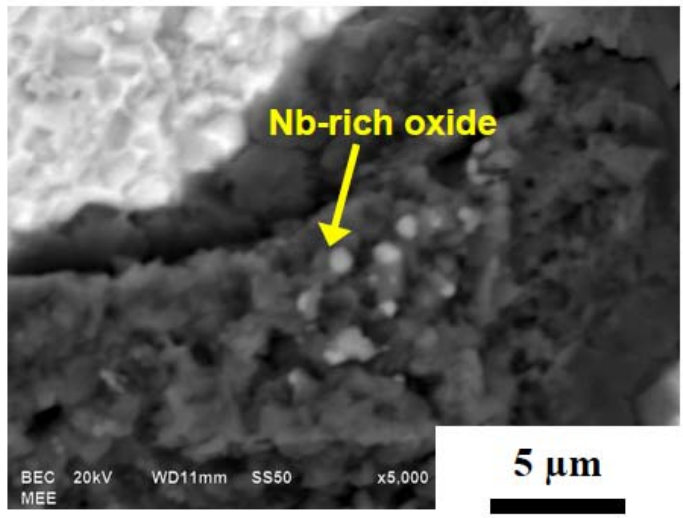

(f)

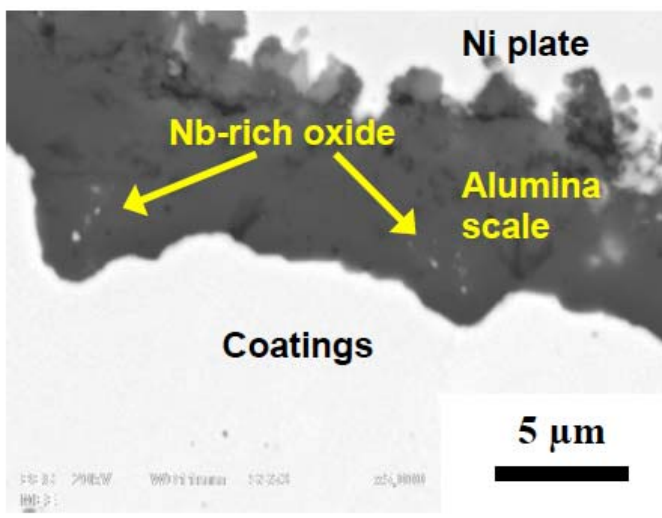

(h)

Figure 12: SEM backscattered electron of the Pt-NiAl coating oxidized at $1050^{\circ} \mathrm{C}$. Surface (a) after $100 \mathrm{~h}$; (b) after $500 \mathrm{~h}$; (c) after $1500 \mathrm{~h}$; (d) after 2560h; (e) and (f) after 4070h, and cross-section (g) and (h) after 4070h. 


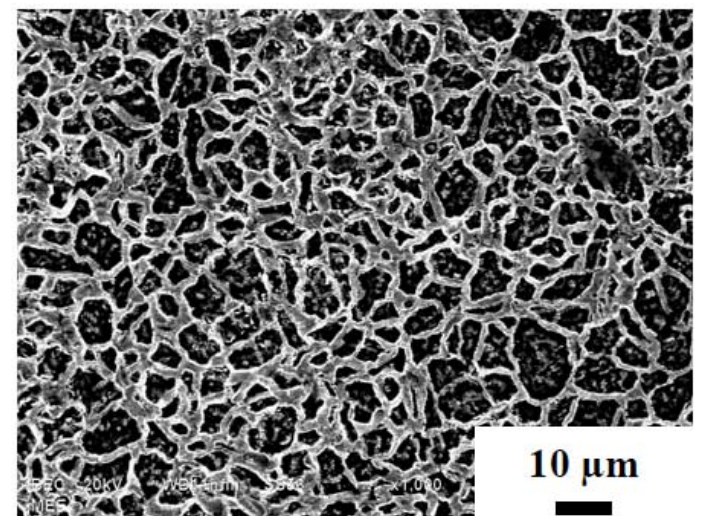

(a)

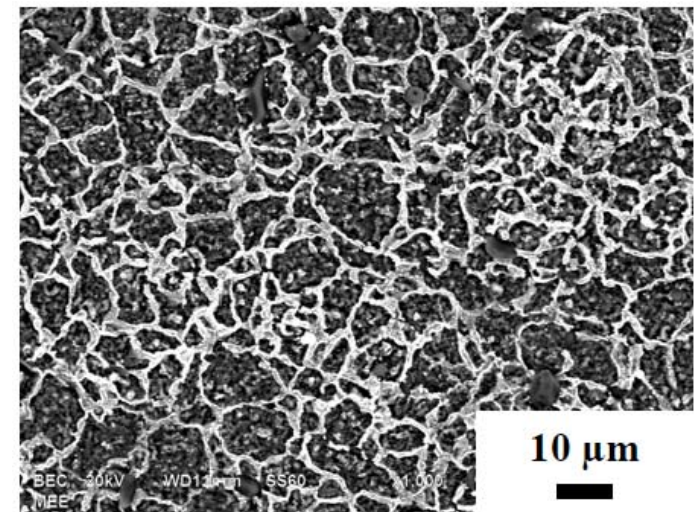

(c)

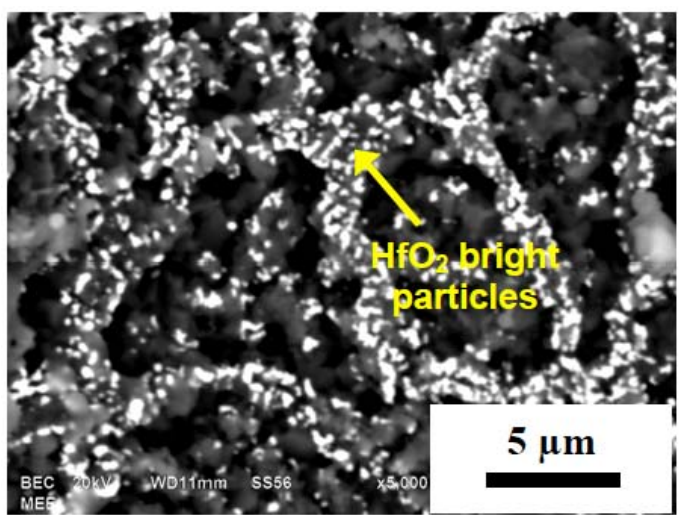

(e)

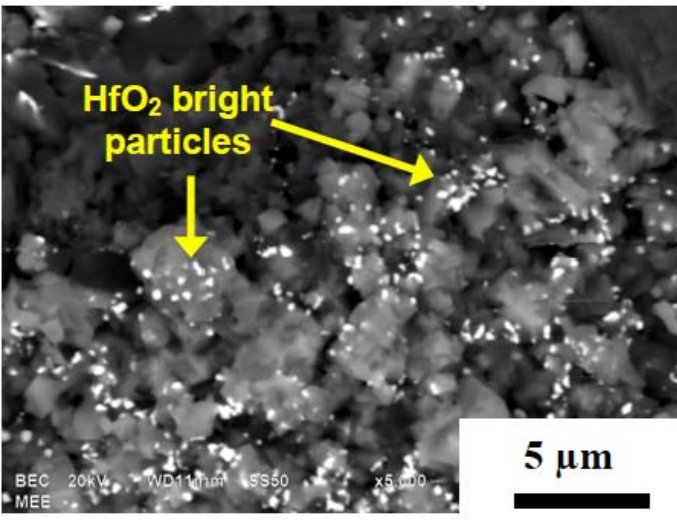

(g)

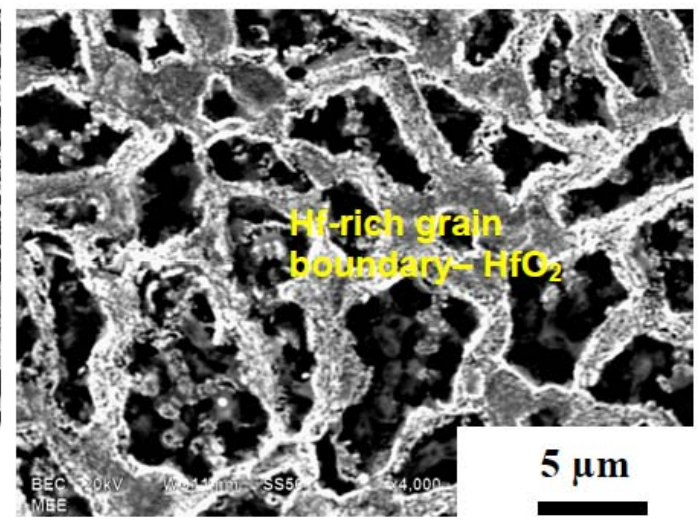

(b)

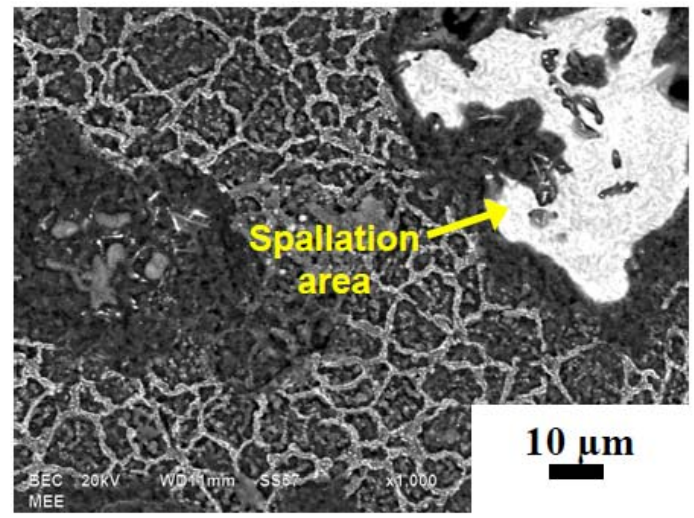

(d)

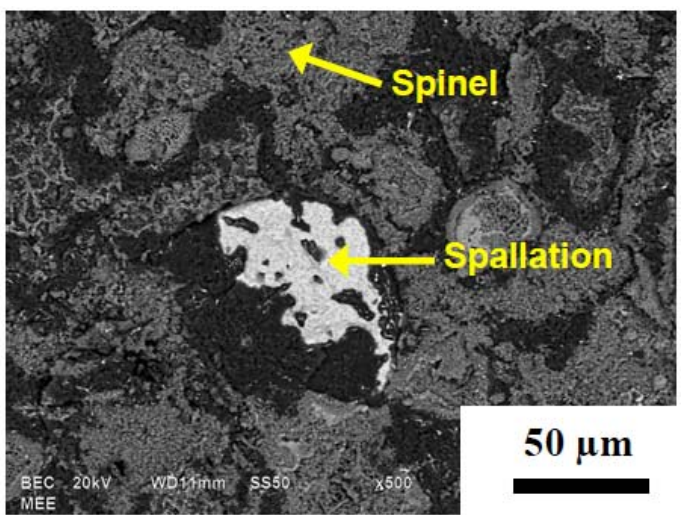

(f)

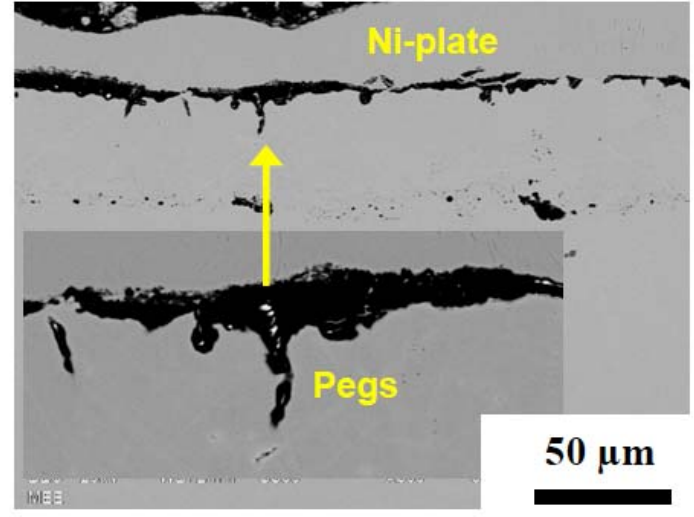

(h)

Figure 13: SEM backscattered electron micrographs of the $\mathrm{Hf}-\mathrm{Pt}-\mathrm{NiAl}$ coating oxidized at $1050^{\circ} \mathrm{C}$. Surface (a and b) after $100 \mathrm{~h}$; (c) after $500 \mathrm{~h}$; (d) after 1500h; (e) after 2560h; (f and g) after 4370h; and cross-section (h) after 4370h. 
$\mathrm{NiAl}$ coatings showed a composition about $2 \mu \mathrm{m}$ below the alumina scale of $54.1 \mathrm{Ni}-3.6 \mathrm{Al}-15.2 \mathrm{Cr}-15.1 \mathrm{Fe}-1.1 \mathrm{Ti}-4.9 \mathrm{Nb}-$ $6 \mathrm{Pt}$ (wt. \%). This confirms XRD showing substantial transformation from the original $\beta-(\mathrm{Ni}, \mathrm{Pt}) \mathrm{Al}+\xi-\mathrm{PtAl}_{2}$ to $\mathrm{\gamma}$ $\mathrm{Ni}_{\text {soln. }}$ and indicates the incorporation of $\mathrm{Cr}, \mathrm{Fe}, \mathrm{Nb}$, and $\mathrm{Ti}$.

\subsubsection{Hf-Pt-NiAl Coating}

The Hf-Pt-NiAl coating was inspected by SEM at $100 \mathrm{~h}, 500 \mathrm{~h}$, $1500 \mathrm{~h}, 2560 \mathrm{~h}$, and after terminating at $4370 \mathrm{~h}$. At $100 \mathrm{~h}$, dense $\mathrm{Al}_{2} \mathrm{O}_{3}$ oxide scales were formed with no apparent spallation (Figure 13a). The distinct $\mathrm{Hf}$-rich ridge structure of the coating was emphatically replicated by bright particles as a Hf-rich oxide, presumably $\mathrm{HfO}_{2}$ (Figure 13b) [39]. The same features were maintained after 500h (Figure 13c). Spalling and deviation from the projected isothermal weight curve was projected to start at $520 \mathrm{~h}$, so adherent scales were expected. However, after $1500 \mathrm{~h}$ the weight change has just reached its maximum. Localized spallation is now observed with individual spall segments spanning a number of the prior ridge features (Figure 13d). The same general structure was observed after $2560 \mathrm{~h}$, but now with a more distinctly coarsened $\mathrm{HfO}_{2}$ particulate, (Figure 13e). The bright spalled areas were rich in $\mathrm{Ni}, \mathrm{Al}, \mathrm{Nb}, \mathrm{Pt}, \mathrm{Cr}$, and $\mathrm{Fe}$, (but no oxygen) indicating the exposed metal surface of the coating. The weight change was in a steady linear decline at this point. Finally, after $4370 \mathrm{~h}$, spallation continued such that large areas of spalled and re-oxidized surfaces were evident as grey $\mathrm{Ni}, \mathrm{Cr}$-rich scales in contrast to dark $\mathrm{Al}_{2} \mathrm{O}_{3}$, Figure $\mathbf{1 3 f}$. This is somewhat consistent with XRD results showing $\alpha$ $\mathrm{Al}_{2} \mathrm{O}_{3}$, spinel, and $\mathrm{Ti}(\mathrm{Nb}) \mathrm{O}_{2}$ rutile. The fine, bright $\mathrm{HfO}_{2}$ particles were still present, as confirmed by XRD, but now positioned on top of a base of grey spinel scale (Figure 13g). At lower magnification, the optical micrograph of the oxidized surface showed less degree of spalling than the Pt-NiAl coating, Figures $\mathbf{8} \mathbf{d}$ and $\mathbf{e}$, and in a more random pattern.

The polished cross-section showed that the surface was relatively flat (Figure 13h), with less rumpling compared to the failed Pt-NiAl coatings. As with the Hf-NiAl coating without $\mathrm{Pt}, \mathrm{Al}_{2} \mathrm{O}_{3}$ oxide pegs were observed with bright $\mathrm{HfO}_{2}$ particles

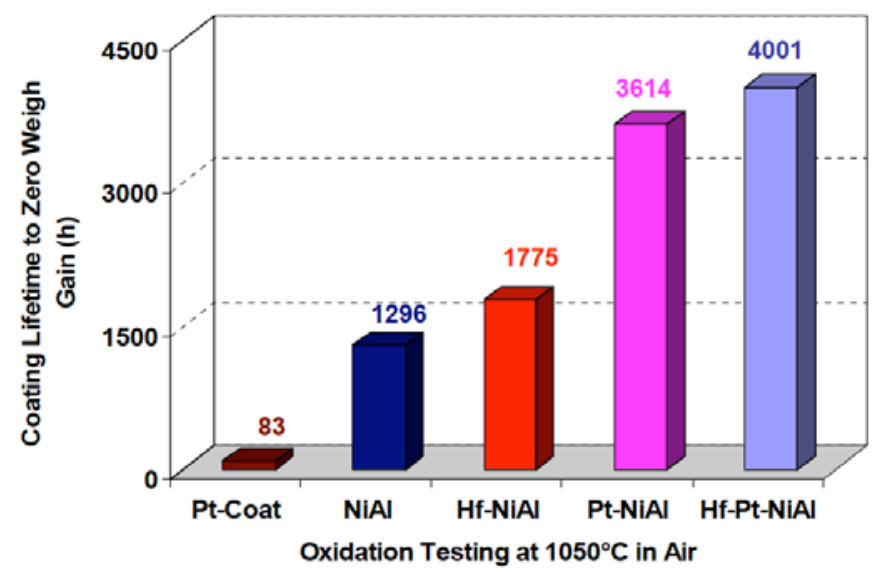

(a) inside. The coating composition was $53.6 \mathrm{Ni}-2.2 \mathrm{Al}-16.6 \mathrm{Cr}$ 16.8Fe-1.1Ti-4.4Nb-5.3Pt (wt. \%) about $2 \mu \mathrm{m}$ below the alumina scale interface. The original Hf-Pt-modified $\beta$ $(\mathrm{Ni}, \mathrm{Pt}) \mathrm{Al}$ coating transformed into $\mathrm{\gamma}-\mathrm{Ni}_{\text {soln }}$, as confirmed by $\mathrm{XRD}$, with considerable increase in $\mathrm{Cr}, \mathrm{Fe}$ and $\mathrm{Nb}$ content.

\section{DISCUSSION}

The Pt diffused coating failed in less than $100 \mathrm{~h}$ because of the low $\mathrm{Al}$ content in this system and the formation of $\mathrm{Cr}_{2} \mathrm{O}_{3}$ instead of $\mathrm{Al}_{2} \mathrm{O}_{3}$ scales. $\mathrm{Cr}_{2} \mathrm{O}_{3}$ scales grow faster and are more susceptible to spallation at temperatures $\sim 1000^{\circ} \mathrm{C}$ and degrade by volatilization of $\mathrm{Cr}_{2} \mathrm{O}_{3}$ (s) to $\mathrm{CrO}_{3}$ (g) [58-59]. Though ineffective on Inconel 718, diffused Pt coatings are quite successful on higher aluminum Ni-base superalloys where $\mathrm{Al}_{2} \mathrm{O}_{3}$ scales can be formed on $\mathrm{Y}-\mathrm{Ni}+\mathrm{y}^{\prime}-\mathrm{Ni}_{3} \mathrm{Al}$ twophase alloys [32].

In contrast with the Pt-coating, the other four coatings showed significantly better oxidation resistance. The coating lifetime, arbitrarily defined as the oxidation testing time to zero weight change, was summarized in Figure 14a. The addition of $\mathrm{Hf}$ to the NiAl and Pt-NiAl coatings increased the lifetime $\sim 37 \%$ (from $1296 \mathrm{~h}$ to $1775 \mathrm{~h}$ ) and $11 \%$ (from $3614 \mathrm{~h}$ to 4001h), respectively. Alternatively, the coating lifetime depends on the oxidation behavior of the surface composition as well as the coating thickness and $\mathrm{Al}$ reservoir. If the coating thickness is considered, $\mathrm{Hf}$ additions increased the normalized coating lifetime $\sim 46 \%$ (from $20.9 \mathrm{~h} / \mu \mathrm{m}$ to 30.6 $\mathrm{h} / \mu \mathrm{m}$ ) and $\sim 58 \%$ (from $35.8 \mathrm{~h} / \mu \mathrm{m}$ to $56.4 \mathrm{~h} / \mu \mathrm{m}$ ), respectively, Figure 14b. This approximate ranking suggests that $\mathrm{Hf}-\mathrm{Pt}-$ $\mathrm{NiAl}>\mathrm{Pt}-\mathrm{NiAl}>\mathrm{Hf}-\mathrm{NiAl}>\mathrm{NiAl}>\mathrm{Pt}$-diffusion coatings. The beneficial effect of $\mathrm{Hf}$-doping is in an agreement with the previous studies on Hf-doped cast NiAl alloys [25, 29, 31], though our present results represent only a limited number of samples.

The parabolic oxidation rate constant $\mathrm{k}_{\mathrm{p}}$ can be represented by [56]:

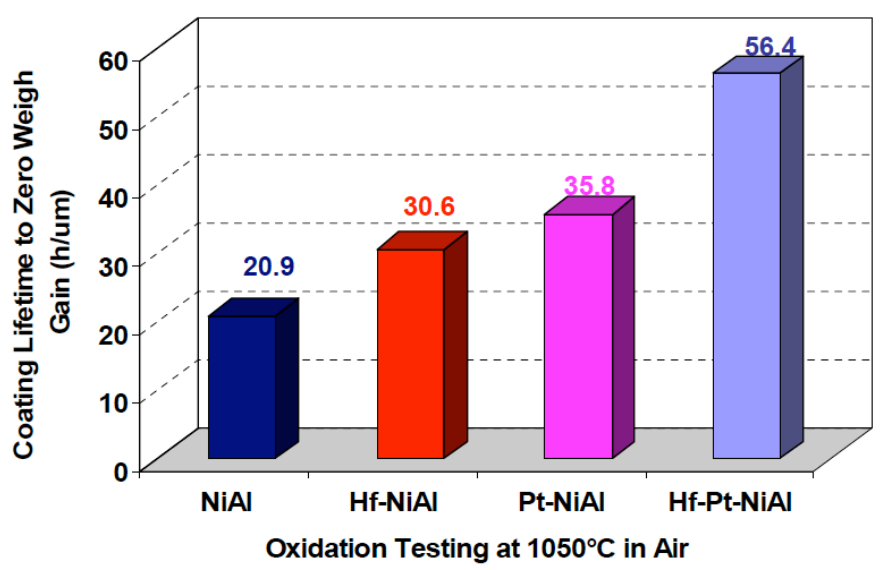

(b)

Figure 14: Coating lifetime to zero weight gain at $1050^{\circ} \mathrm{C}$ (a) Raw lifetime; (b) Lifetime normalized by coating thickness. 
$\left(\Delta m-\Delta m_{i}\right)^{2}=k_{p}\left(t-t_{i}\right)$

$\Delta m-\Delta m_{i}=\left\{k_{p}\left(t-t_{i}\right)\right\}^{1 / 2}$

where $\Delta \mathrm{m}$ is the weight change at time t, and $\Delta \mathrm{m}_{\mathrm{i}}$ is the weight change associated with the transient period $t_{i}$ of initial fast oxidation into steady state oxidation. In equation (1), the initial weight gain is corrected out to allow calculation of the parabolic rate constant. Better parabolic fits were obtained by eqn. $1 \mathrm{~b}$, as discussed in section 3.1 and summarized in Table 2. The results indicate similar $\mathrm{k}_{\mathrm{p}}$ for the $\mathrm{Pt}, \mathrm{Hf}$, and $\mathrm{Hf}-$ Pt-doped aluminide coatings. Interestingly enough, however, these values were all greater than that for the simple aluminide, which, in turn, was above that for the commercial MDC150L Pt-modified aluminide. An optimally doped Hf-NiAl coating should decrease $k_{p}$ significantly. The high rates obtained here can be attributed to excess $\mathrm{HfO}_{2}$ formation from the 0.3-0.4 wt. \% $\mathrm{Hf}$ coating surface and additional internal oxidation as $\mathrm{HfO}_{2}$-initiated oxide pegs. It is more difficult to explain the high rate of the Pt-NiAl coating. Perhaps it was associated with the increased cusped surface area or some undesirable effect of the $\mathrm{PtAl}_{2}$ second phase.

The composition of the Hf-NiAl coating prior to testing was around Ni-32.0Al-7.5Cr-15.3Fe, with $\sim 0.1 \mathrm{Hf}_{\text {avg. }}$ (wt. \%). It has been reported [29] that the $1100^{\circ} \mathrm{C}$ parabolic rate constants $\mathrm{k}_{\mathrm{p}}$ from cast bulk alloys of NiAl-5Cr-0.05 at. \% Hf (Ni-29.5Al$6.0 \mathrm{Cr}-0.2 \mathrm{Hf}$, wt.\%) and $\mathrm{NiAl}-0.05$ at.\%Hf (Ni-31.5Al-0.2wt.\% Hf) were $4.3 \times 10^{-13} \mathrm{~g}^{2} / \mathrm{cm}^{4} / \mathrm{sec}$ and $\sim 0.8 \times 10^{-13} \mathrm{~g}^{2} / \mathrm{cm}^{4} / \mathrm{sec}$, respectively. These are compatible with the present value of $2.6 \times 10^{-13} \mathrm{~g}^{2} / \mathrm{cm}^{4} / \mathrm{sec}$, considering the $50^{\circ} \mathrm{C}$ temperature differential and secondary element ( $\mathrm{Fe}, \mathrm{Ti}, \mathrm{Nb})$ compositional differences that developed (Table 1).

Regarding scale adhesion, it would be expected that $\mathrm{Hf}-$ doping should dramatically improve cyclic behavior compared to the simple aluminide. Accordingly, minor spallation was observed on the NiAl coating after just $100 \mathrm{~h}$, but not on the $\mathrm{Hf}-\mathrm{NiAl}$ coating until the $500 \mathrm{~h}$ examination. Yet deviations from projected parabolic curves and the maximum in weight gain occurred at an earlier time for the Hf-NiAl coating, with a somewhat lower rate of weight loss.

Similar comparisons can be drawn for the Pt-NiAl and Hf-Pt$\mathrm{NiAl}$ coatings. Both deviate from their projected parabolic rate $(\sim 500 \mathrm{~h})$ and reached a maximum $(1500 \mathrm{~h})$ at similar times. At $1500 \mathrm{~h}$ the Pt-NiAl coating only showed cracks in the alumina scales, while the Hf-Pt-NiAl coating already showed spallation. But then the Pt-NiAl coating lost weight more rapidly, eventually following similar curves.

To some extent then the Hf-doped coatings did not exhibit unequivocal, dramatic improvements in scale growth and adhesion as might be expected from the bulk studies. The high concentration of $\mathrm{Hf}$ in the coating surface resulted in a high concentration of $\mathrm{HfO}_{2}$ particles at coating grain boundaries and within the scales, sized from less than 100 nanometers to several microns. Furthermore, $\mathrm{Hf}$ played a role in the initiation and growth of $\mathrm{Al}_{2} \mathrm{O}_{3}$ intrusions into the metal. This all contributed to an excess in weight gain, though the average thickness may not have been affected as much. To some extent, the production of oxide intrusions may increase stress concentrations in the scale on cooldown and increase spallation. The various phenomena have been described in terms of "over-doping" [60]. Furthermore, the $~ 30$ ppmw S substrate impurity may have been too much for Hf-doping to completely overcome.

Pegging has long been associated with reactive element effects and associated with scale adhesion, though not necessarily proven as cause and effect. Similar Hf-induced oxide pegs have been reported on Hf-doped Co-10 Cr-11Al (wt. \%) cast alloys [20, 22], Hf-doped NiAl cast alloys [25], and $70 \mathrm{Ni20 \textrm {Al }} 7 \mathrm{Cr} 3 \mathrm{Hf}$ (wt. \%) cladding alloys on a Rene 80 substrate [61]. Pegging is thought to be a special borderline case of internal oxidation where oxygen in solution can form $\mathrm{HfO}_{2}$ first, due to its high oxygen affinity $\left(-\Delta G^{\circ}\right.$ of oxide formation) [62], even underneath a newly formed $\mathrm{Al}_{2} \mathrm{O}_{3}$ layer. But rapid oxygen diffusion in $\mathrm{HfO}_{2}$ relative to $\mathrm{Al}_{2} \mathrm{O}_{3}$ allows further penetration, primarily at regions connected to the surface. Eventually, as the $\mathrm{Hf}$ concentration is depleted and the oxygen potential is increased locally at these penetrations, $\mathrm{Al}_{2} \mathrm{O}_{3}$ can form and grow by rapid interfacial diffusion, ultimately embedding the initial $\mathrm{HfO}_{2}$ precipitates [63]. The process is preferred at the Hf-rich areas, such as coating grain boundaries.

While pegging is currently considered a non-causative artifact regarding reactive element effects on scale adhesion, the sulfur content remains to be a critical factor. Briefly, it has been shown repeatedly that ppm levels of sulfur in the bulk can segregate to high levels at the metal surface or oxidemetal interface at high temperature. Reactive element additions prevent deleterious effects on scale adhesion, in large part by reducing the sulfur activity in the alloy and reducing segregation. $\mathrm{Pt}$ is also very effective in counteracting the sulfur effects, however the possible mechanism(s) must be substantially different [11, 12]. In any event, the substrate, baseline and $\mathrm{Hf}$-doped coatings exhibit considerable sulfur contents, 30, 250, and $110 \mathrm{ppmw}$, respectively. Sulfur from both sources may have thus played a major role in deteriorating the cyclic oxidation performance of these samples. While it is known that sulfur impurities enter aluminide coatings in CVD processing [64], the substrate amount could be reduced by using low sulfur $(<1$ ppmw), second generation single crystal superalloys. These substrates, with their higher aluminum contents, should lead to improved cyclic oxidation behavior.

The surface structures presented some familiar and unusual features. In the cited studies of aluminized superalloys, a network of alumina scale ridges was common during protective growth and was the site of fine $\mathrm{HfO}_{2}$ precipitates for those systems with $\mathrm{Hf}$. Such a network was not observed here, possibly due to the fine structure of the coatings and 
the domination of coating grain boundary and cusp-like features. Regarding degraded structures, comparison to some details from an $1150^{\circ} \mathrm{C}, 2000 \mathrm{~h}$ cyclic test of $\mathrm{Ni}(\mathrm{Pt}) \mathrm{Al}$ coated CMSX4 may apply, particularly regarding secondary oxide formations [65]. In one protective sample, the alumina scale grain boundary ridges were decorated with a fine, uniform distribution of monoclinic $(\mathrm{Hf}, \mathrm{Ti}) \mathrm{O}_{2}$ particles. But another sample produced steady state weight losses and exhibited interfacial spallation. Crystallographically faceted $(\mathrm{Ni}, \mathrm{Co})(\mathrm{Al}, \mathrm{Cr})_{2} \mathrm{O}_{4}$ spinel, with an $\alpha-\mathrm{Al}_{2} \mathrm{O}_{3}$ base scale were the dominant features. Other regions exhibited nodular spinel grains, with fine ( $\mathrm{Ta}, \mathrm{Ti})$-rich rutile particles decorating the spinel. The spinel regions were regarded as re-oxidized areas that had previously spalled to bare metal, exposing a surface with insufficient Al content to re-form alumina. Many of these features are represented in the present study.

The cross-sections clearly demonstrated $\mathrm{Al}$ depletion due to the formation of $\mathrm{Al}_{2} \mathrm{O}_{3}$ scales and interdiffusion with the substrate. By contrast, in bulk NiAl cast alloys [13, 41, 66, 2531], Al depletion due to interdiffusion is absent. Doped cast alloys also possess a more uniform $\mathrm{Hf}$ distribution. Consequently, greater cyclic oxidation lifetimes are expected on Hf-doped $\mathrm{NiAl}$ cast alloys than on Hf-modified $\mathrm{NiAl}$ coatings.

Finally, $\mathrm{Hf}$ additions decreased the surface rumpling during oxidation compared to both $\mathrm{NiAl}$ and $\mathrm{Pt}-\mathrm{NiAl}$ coatings. Similar results have been observed during $1150^{\circ} \mathrm{C}$ oxidation testing of a $\mathrm{Ni}(\mathrm{Pt}) \mathrm{Al}$ aluminide coatings on $\mathrm{Ni}$-base substrates with different $\mathrm{Hf}$ contents [40]. Although there are many coupled origins of the rumpling phenomenon [66-68], it is generally agreed that reducing rumpling of the coating can increase the creep strength significantly. The improved creep strength of Hf-doped bulk NiAl has been well documented [70-71]. Decreased bond coat rumpling is expected to increase the adherence of the ceramic top coat and so improve the lifetime of TBC systems in engine service environments [18, 19], as recently demonstrated commercially [49,50].

\section{SUMMARY}

Simple $\beta$-NiAl, Hf-modified $\beta$-NiAl, Pt-diffused, Pt-modified $\beta$ $(\mathrm{Ni}, \mathrm{Pt}) \mathrm{Al}+\xi-\left(\mathrm{PtAl}_{2}\right)$, and $\mathrm{Hf}$-modified $\beta-(\mathrm{Ni}, \mathrm{Pt}) \mathrm{Al}$ coatings were produced on Inconel-718 substrates and tested in cyclic $1050^{\circ} \mathrm{C}$ oxidation in air up to $4370 \mathrm{~h}$, showing:

(1) Hf additions to both simple aluminide and Pt-modified aluminide coatings improved the adherence of oxide scales, reduced rumpling, and extended the coating lifetime.

(2) Both $\mathrm{Hf}$-doped coatings formed an outer surface network of $\mathrm{Hf}$-rich ridges at the coating grain boundaries that oxidized to dispersed $\mathrm{HfO}_{2}$ particles; $\mathrm{Hf}$-rich areas also oxidized to $\mathrm{HfO}_{2}$ particles embedded within the $\alpha-\mathrm{Al}_{2} \mathrm{O}_{3}$ scales and as intrusions in the metal (pegs).
(3) Pt-doping was very effective in improving the cyclic oxidation behavior in both the Pt-NiAl and Hf-Pt-NiAl coatings.

(4) Optimum adhesion and growth behavior may not have been demonstrated because of high initial sulfur and low aluminum contents in the alloy, over-doping with $\mathrm{Hf}$ resulting in excess $\mathrm{HfO}_{2}$ formation, and secondary effects due to substrate $\mathrm{Fe}, \mathrm{Ti}, \mathrm{Nb}$ diffusion into the coating.

(5) Diffused Pt coatings without aluminizing did not exhibit any noticeable oxidation protection due to the low Al content of the Inconel 718 substrate and intrinsic inability to form alumina scales.

\section{ACKNOWLEDGEMENTS}

This work is a part of SIFCO Hf-modified aluminide coating research and development program with a goal to investigate the beneficial effects of $\mathrm{Hf}$ additions during 2008-2011. Program management support by Jeff Thrun, Mike Christopher, Tom Anderson, Jerry Oss, Dan Lindau; vapor phase coating process and heat treatment support by Guy Sayre; metallurgical sample preparation by Randy Watkins; SEM/EDS analysis by Dieter Scholz at Materials Engineering and Evaluation; GDMS analysis by Karol Putyera at Evans Analytical Group; and XRD analysis of surface scales by Richard B. Rogers of NASA GRC are gratefully acknowledged.

\section{REFERENCES}

[1] Hindam H, Whittle DP. Microstructure, adhesion and growth kinetics of protective scales on metals and alloys. Oxid Met 1982; 18 (5-6): 245-284.

http://dx.doi.org/10.1007/BF00656571

[2] Miller RA. Oxidation-based model for thermal barrier coating life. J Am Ceram Soc 1984; 67 (8) 517-521. http://dx.doi.org/10.1111/j.1151-2916.1984.tb19162.x

[3] DeMasi-Marcin JT, Sheffler KD, Bose S. Mechanisms of degradation and failure in a plasma-deposited thermal barrier coating. J Eng Gas Turbine Power 1990; 112 (4): 521-526. http://dx.doi.org/10.1115/1.2906198

[4] Cocking JL, Richards PG, Johnston GR. Comparative durability of six coating systems on first-stage gas turbine blades in the engines of a long-range maritime patrol aircraft. Surf Coat Technol 1988; 36:37-47. http://dx.doi.org/10.1016/0257-8972(88)90134-X

[5] Krishna GR, Das DK, Singh V, Joshi SV. Role of Pt content in the microstructural development and oxidation performance of Ptaluminide coatings produced using a high-activity aluminizing process. Mater Sci Eng A 1988; 251: 40-47.

http://dx.doi.org/10.1016/S0921-5093(98)00655-8

[6] Fisher G, Chan WY, Datta PK, Burnell-Gray JS. Noble metal aluminide coatings for gas turbines. Platinum Met Rev 1999; 43(2): 59-61.

[7] Zhang Y, Haynes JA, Lee WY, Wright IG, Pint BA, Cooley KM, Liaw $\mathrm{PK}$. Effects of Pt incorporation on the isothermal oxidation behavior of chemical vapor deposition aluminide coatings. Metall Mater Trans A 2001; 32: 1727-1741.

http://dx.doi.org/10.1007/s11661-001-0150-6

[8] Haynes JA, Pint BA, Zhang Y, Wright IG. The effect of Pt content on $Y-Y^{\prime}$ NiPtAl coatings. Surf Coat Technol 2008; 203 (5-7): 413-416. http://dx.doi.org/10.1016/i.surfcoat.2008.08.063

[9] Reed RC, Wu RT, Hook MS, Rae CMF, Wing RG. On oxidation behaviour of platinum aluminide coated nickel based superalloy CMSX-4. Mater Sci Technol 2009; 25 (2): 276-286. http://dx.doi.org/10.1179/174328408X361481 
[10] Warnes BM, Punola DC. Clean diffusion coatings by chemical vapor deposition. Surf Coat Technol 1997; 94-95: 1-6. http://dx.doi.org/10.1016/S0257-8972(97)00467-2

[11] Hou PY. Segregation phenomena at thermally grown $\mathrm{Al}_{2} \mathrm{O}_{3} /$ alloy interfaces. Annu Rev Mater Res 2008; 38: 275-298.

http://dx.doi.org/10.1146/annurev.matsci.38.060407.130323

[12] Gheno T, Monceau D, Oquab D, Cadoret Y. Characterization of sulfur distribution in Ni-based superalloy and thermal barrier coatings after high temperature oxidation: A SIMS analysis. Oxid Met 2010; 73 (12): 95-113.

http://dx.doi.org/10.1007/s11085-009-9164-z

[13] Gleeson B, Wang W, Hayashi S, Sordelet D. Effects of platinum on the interdiffusion and oxidation behavior of Ni-Al-based alloys. Mater Sci Forum 2004; 461-464: 213-222.

http://dx.doi.org/10.4028/www.scientific.net/MSF.461-464.213

[14] Copland E. Thermodynamic effect of platinum addition to $\beta$-NiAl: An initial investigation. NASA/CR-2005-213330, NASA, Cleveland, OH, 2005, pp1-28.

[15] Gleeson B, Mu N, Hayashi S. Compositional factors affecting the establishment and maintenance of $\mathrm{Al}_{2} \mathrm{O}_{3}$ scales on Ni-Al-Pt systems. J Mater Sci 2009; 44 (7): 1704-1710.

http://dx.doi.org/10.1007/s10853-009-3251-Z

[16] Zhang Y, Haynes JA, Pint BA, Wright IG, Lee WY. Martensitic transformation in CVD NiAl and (Ni,Pt)Al bond coatings, Surf Coat Technol 2003; 163 -164: 19-24.

[17] Chen MW, Ott RT, Hufnagel TC, Wright PK, Hemker KJ. Microstructural evolution of platinum modified nickel aluminide bond coat during thermal cycling. Surf Coat Technol 2003; $163-164$ : 2530 .

[18] Tolpygo VK, Clarke DR. Surface rumpling of a (Ni,Pt)Al bond coat induced by cyclic oxidation. Acta Mater 2000; 48: 3283-3293.

\section{http://dx.doi.org/10.1016/S1359-6454(00)00156-7}

[19] Mumm DR, Evans AG, Spitsberg IT. Characterization of a cyclic displacement instability for a thermally growth oxide in a thermal barrier system. Acta Mater 2001; 49: 2329-2340. http://dx.doi.org/10.1016/S1359-6454(01)00071-4

[20] Stringer J, Allam M, Whittle DP. The high temperature oxidation of Co-Cr-Al alloys containing yttrium or hafnium additions. Thin Solid Films 1977; 45:377-384. http://dx.doi.org/10.1016/0040-6090(77)90273-5

[21] Allam IM, Whittle DP, Stringer J. The oxidation behavior of CoCrAl systems containing active element additions. Oxid Met 1978; 12 (1) 35-66. http://dx.doi.org/10.1007/BF00609974

[22] Allam IM, Whittle DP, Stringer J. Improvements in oxidation resistance by dispersed oxide addition: $\mathrm{Al}_{2} \mathrm{O}_{3}$-forming alloys. Oxid Met 1979; 13 (4) 381-401. http://dx.doi.org/10.1007/BF00609306

[23] Pendse R, Stringer J. The influence of alloy microstructure on the oxide peg morphologies in a Co-10\% Cr-11\%Al alloy with and without reactive element additions. Oxid Met 1985; 23 (1-2): 1-16. http://dx.doi.org/10.1007/BF01095804

[24] Khanna AS, Wasserfuhr C, Quadakkers WJ, Nickel H. Addition of yttrium, cerium and hafnium to combat the deleterious effect of sulphur impurity during oxidation of a Ni---Cr---Al alloy. Mater Sci Eng A 1989; 120: 185-191.

http://dx.doi.org/10.1016/0921-5093(89)90738-7

[25] Pint PA, Wright IG, Lee WY, Zhang Y, Prüßner K, Alexander KB. Substrate and bond coat compositions: factors affecting alumina scale adhesion. Mater Sci Eng A 1998; 245: 201-211.

http://dx.doi.org/10.1016/S0921-5093(97)00851-4

[26] Pint BA, Haynes JA, More KL, Wright IG, Leyens C. Compositional effects on aluminide oxidation performance: objectives for improved bond coats. In: Pollock TM, Kissinger RD, Bowman RR, Green KA, McLean M, Olson S, Schirra JJ, editors. Superalloys 2000, TMS (7th Minerals, Metals \& Materials Society); 2000: p. 629-638.

[27] Leyens C, Pint BA, Wright IG. Effect of composition on the oxidation and hot corrosion resistance of NiAl doped with precious metals. Surf Coat Technol 2000; 133-134: 15-22.

http://dx.doi.org/10.1016/S0257-8972(00)00878-1

[28] Haynes JA, Pint PA, More KL, Zhang Y, Wright IG. Influence of sulfur, platinum, and hafnium on the oxidation behavior of CVD NiAl bond coatings. Oxid Met 2002; 58 (5-6): 513-544. http://dx.doi.org/10.1023/A:1020525123056

[29] Pint BA, More KL, Wright IG. Effect of quaternary additions on the oxidation behavior of Hf-doped NiAl. Oxid Met 2003; 59 (3-4): 257283.

http://dx.doi.org/10.1023/A:1023087926788
Pint BA. The role of chemical composition on the oxidation performance of aluminide coatings. Surf Coat Technol 2004; 188189: $71-78$.

http://dx.doi.org/10.1016/i.surfcoat.2004.08.007

[31] Pint BA, Haynes JA, Besmann TM. Effect of $\mathrm{Hf}$ and $\mathrm{Y}$ alloy additions on aluminide coating performance. Surf Coat Technol 2010; 204: 3287-3293.

http://dx.doi.org/10.1016/i.surfcoat.2010.03.040

[32] Izumi T, Mu N, Zhang L, Gleeson B. Effects of targeted $y-\mathrm{Ni}+\gamma^{\prime}-\mathrm{Ni}$ i3Abased coating compositions on oxidation behavior. Surf Coat Technol 2007; 202: 628-631.

http://dx.doi.org/10.1016/i.surfcoat.2007.08.014

[33] Pint BA. Optimization of reactive-element additions to improve oxidation performance of alumina-forming alloys. J Am Ceram Soc 2003; 86 (4): 686-695.

http://dx.doi.org/10.1111/j.1151-2916.2003.tb03358.x

[34] Pint BA, Schneibel JH. The effect of carbon and reactive element dopants on oxidation lifetime of FeAl. Scripta Mater 2005; 52:11991204.

http://dx.doi.org/10.1016/i.scriptamat.2005.03.008

[35] Gupta DK, Duvall DS. A silicon and hafnium modified plasma sprayed MCrAlY coating for single crystal superalloys. In: Gell M, Kortovich CS, Bricknell RH, Kent WB, Radavich JF, editors. Superalloys 1984, TMS, Warrendale, PA;1984: p. 711-720. http://dx.doi.org/10.7449/1984/Superalloys 1984711720

[36] Whittle DP, Stringer J. Improvement in properties: additives in oxidation resistance. Phil. Trans. R. Soc. Lond. A 1980; 295: 309-329. http://dx.doi.org/10.1098/rsta.1980.0124

[37] Meier GH. Research on oxidation and embrittlement of intermetallic compounds in the U.S. Mater Corros 1996; 47: 595-618.

[38] Stringer J. The reactive element effect in high-temperature corrosion. Mater Sci Eng A 1989; 120-121: 129-137.

http://dx.doi.org/10.1016/0921-5093(89)90730-2

[39] Pint BA. Experimental observations in support of the dynamicsegregation theory to explain the reactive-element effect. Oxid Met 1996; 45 (1-2): 1-37.

http://dx.doi.org/10.1007/BF01046818

[40] Smialek JL, Lowell CE. Effects of diffusion on aluminum depletion and degradation of NiAl coatings. J Electrochem Soc 1974; 121 (6): 800805.

http://dx.doi.org/10.1149/1.2401922

[41] Zhang Y, Stacy JP, Pint BA, Haynes JA, Hazel BT, Nagaraj BA. Interdiffusion behavior of Pt-diffused $\gamma+\gamma^{\prime}$ coatings on Ni-based superalloys. Surf Coat Technol 2008; 203: 417-421.

http://dx.doi.org/10.1016/..surfcoat.2008.08.053

[42] Tolpygo VK, Murphy KS, Clarke DR. Effect of Hf, $Y$ and $C$ in the underlying superalloy on the rumpling of diffusion aluminide coatings. Acta Mater 2008; 56: 489-499.

http://dx.doi.org/10.1016/i.actamat.2007.10.006

[43] Muamba JMN, Streiff R, Boone DH. L'Influence du Hafnium du Substrat sur la R6sistance a l'Oxydation des Rev6tements d'Aluminiures sur les Superalliages Base Nickel ${ }^{*}$ (oxidation of $\mathrm{Hf}$ modified substrate). Mater Sci Eng 1987; 88: 111-121. http://dx.doi.org/10.1016/0025-5416(87)90074-7

[44] Streiff R, Muamba JMN. Mechanisms of the hafnium effect in hightemperature oxidation of aluminide coatings. JOM 1988; 40 (11): 104.

[45] Warnes BM. Reactive element modified chemical vapor deposition low activity platinum aluminide coatings. Surf Coat Technol 2001; 146-147: 7-12. http://dx.doi.org/10.1016/S0257-8972(01)01363-9

[46] Kim GY, He LM, Meyer JD, Quintero A, Haynes JA, Lee WY. Mechanisms of $\mathrm{Hf}$ dopant incorporation during the early stage of chemical vapor deposition aluminide coating growth under continuous doping conditions. Metall Mater Trans A 2004; 35:3581-3593. http://dx.doi.org/10.1007/s11661-004-0194-5

[47] Haynes JA, Zhang Y, Cooley KM, Walker L, Reeves KS, Pint BA. High-temperature diffusion barriers for protective coatings. Surf Coat Technol 2004; 188-189: 153-157.

http://dx.doi.org/10.1016/i.surfcoat.2004.08.066

[48] Ford S, Kartono R, Young R. Oxidation resistance of Pt-modified $\mathrm{V} / \mathrm{y}^{\prime}$ $\mathrm{Ni}-\mathrm{Al}$ at $1150^{\circ} \mathrm{C}$. Surf Coat Technol 2010; 204: 2051-2054. http://dx.doi.org/10.1016/i.surfcoat.2009.08.027

[49] Murphy KS, inventor; Howmet Corporation, assignee. Pt-Al-Hf/Zr Coating and Method. U.S. Patent Application, 2010/0297471 A1, Nov. 25, 2010.

[50] Hazel B, Rigney J, Gorman M, Boutwell B, Darolia R. Development of improved bond coat for enhanced turbine durability. In: Reed RC, 
Green KA, Caron P, Gabb TP, Fahrmann MG, Huron ES, Woodard SA, editors. Superalloys 2008, TMS, Champion, PA; 2008: p.753-760. http://dx.doi.org/10.7449/2008/Superalloys 2008753760

[51] Wang YQ, Suneson M, Sayre G. Synthesis of Hf-modified aluminide coatings on Ni-base superalloys. Surf Coat Technol 2011; 206: 12181228.

http://dx.doi.org/10.1016/i.surfcoat.2011.08.031

[52] Wang YQ, Sayre G. Factors affecting the microstructure of platinummodified aluminide coatings during a vapor phase aluminizing process. Surf Coat Technol 2009; 203: 1264-1272.

http://dx.doi.org/10.1016/j.surfcoat.2008.10.031

[53] Zhang $\mathrm{Y}$, Wang $\mathrm{YQ}$. Effect of $\mathrm{Hf}$ additions on aluminide coatings and oxidation performance, unpublished research experimental data partial data were included in Wang YQ's Ph.D. Dissertation, 2006.

[54] Smialek JL. Effect of sulfur removal on $\mathrm{Al}_{2} \mathrm{O}_{3}$ scale adhesion. Metall Trans A 1991; 22: 739-752 http://dx.doi.org/10.1007/BF02670297

[55] Meier GH, Pettit FS, Smialek JL. The effects of reactive element additions and sulfur removal on the adherence of alumina to $\mathrm{Ni}$ - and Fe-base alloys. Mater Corros 1995; 46: 232-240. http://dx.doi.org/10.1002/maco.19950460407

[56] Pieraggi B. Calculations of parabolic reaction rate constants. Oxid Met 1987; 27 (3-4): 177-185 http://dx.doi.org/10.1007/BF00667057

[57] Rybicki GC, Smialek JL. Effect of the $\theta-\alpha-A l 2 O 3$ transformation on the oxidation behavior of $\beta-\mathrm{NiAl}+\mathrm{Zr}$. Oxid Met 1989; 31 (3-4): 275-304. http://dx.doi.org/10.1007/BF00846690

[58] Graham HC, Davis $\mathrm{HH}$. Oxidation/vaporization kinetics of $\mathrm{Cr}_{2} \mathrm{O}_{3}$. J Am Ceram Soc 1971; $54: 89-93$

http://dx.doi.org/10.1111/j.1151-2916.1971.tb12225.x

[59] Tedmon CS, Jr. The effect of oxide volatilization on the oxidation kinetics of $\mathrm{Cr}$ and $\mathrm{Fe}-\mathrm{Cr}$ alloys. J Electrochem Soc 1966; 113 (8): 766-768

http://dx.doi.org/10.1149/1.2424115

[60] Pint BA. Progress in understanding the reactive element effect since the Whittle and Stringer literature review. In: Tortorelli PF, Wright IG, Hou PY, editors. Proc. John Stringer Symposium on High Temperature Corrosion. ASM International, Materials Park, $\mathrm{OH}$, 2003:p. 9-19.

[61] Ribaudo C, Sircar S, Mazumder J. Laser-clad Ni70Al20Cr7Hf3 alloys with extended solid solution of $\mathrm{Hf}$ : Part II. Oxidation behavior. Metall Mater Trans A 1989; 20: 2489-2497.

http://dx.doi.org/10.1007/BF02666684
[62] Grabke HJ. Segregation and oxidation. Materiali In Tehnologije 2006;40: 39-47.

[63] Hindam $\mathrm{H}$, Whittle DP. Peg formation by short-circuit diffusion in $\mathrm{Al}_{2} \mathrm{O}_{3}$ scales containing oxide dispersions. J Electrochem Soc 1982; 129 (5): 1147-1149.

http://dx.doi.org/10.1149/1.2124044

[64] Lee WY, Zhang Y, Wright IG, Pint BA, Liaw PK. Effects of sulfur impurity on the scale adhesion behavior of a desulfurized Ni-based superalloy aluminized by chemical vapor deposition. Metall Mater Trans A 1998; 29: 833-841.

http://dx.doi.org/10.1007/s11661-998-0274-z

[65] Mialek JL, Garg A. A compendium of scale surface microstructures: $\mathrm{Ni}(\mathrm{Pt}) \mathrm{Al}$ coatings oxidized at $1150^{\circ} \mathrm{C}$ for 2000 1-hr cycles. NASA/TM-2010-216091, NASA, Washington, D.C., Feb.5, 2010.

[66] Göbel M, Rahmel A, Schütze M. The isothermal-oxidation behavior of several nickel-base single-crystal superalloys with and without coatings. Oxid Met 1993; 39 (3-4): 231-261.

http://dx.doi.org/10.1007/BF00665614

[67] Tolpygo VK, Clarke DR. On the rumpling mechanism in nickelaluminide coatings Part I: an experimental assessment. Acta Mate 2004; 52: 5115-5127.

http://dx.doi.org/10.1016/j.actamat.2004.07.023

[68] Tolpygo VK, Clarke DR. On the rumpling mechanism in nickelaluminide coatings Part II: characterization of surface undulations and bond coat swelling. Acta Mater 2004; 52: 5129-5141. http://dx.doi.org/10.1016/i.actamat.2004.07.023

[69] Tolpygo VK, Clarke DR. Rumpling of CVD (Ni,Pt)Al diffusion coatings under intermediate temperature cycling. Surf Coat Technol 2009; 203: 3278-3285.

http://dx.doi.org/10.1016/i.surfcoat.2009.04.016

[70] Locci IE, Dickerson R, Bowman R, Whittenberger JD, Nathal MV Darolia R. Microstructure and mechanical properties of cast, homogenized and aged NiAl single crystal containing Hf. In Baker I, Darolia R, Whittenberger JD, Yoo MH, editors. High-Temperature Ordered Intermetallic Alloys V; Mater. Res. Soc. Symp. Proc. 288 Pittsburgh, PA 1993; 288: 685-690.

[71] Noebe R, Bowman R. Review of the physical and mechanical properties and potential applications of the compound NiAl. International Mater Rev 1993; 38: 193-232. http://dx.doi.org/10.1179/imr.1993.38.4.193

(C) 2014 Wang et al.; Licensee Lifescience Global.

This is an open access article licensed under the terms of the Creative Commons Attribution Non-Commercial License (http://creativecommons.org/licenses/by-nc/3.0/) which permits unrestricted, non-commercial use, distribution and reproduction in any medium, provided the work is properly cited. 